\title{
Multiscale Dynamics of the February 11-12, 2010, Deep South US Snowstorm Event
}

\author{
Stephany M. Taylor, ${ }^{1}$ Michael L. Kaplan, ${ }^{2}$ and Yuh-Lang Lin ${ }^{1,3}$ \\ ${ }^{1}$ Department of Energy \& Environmental Systems, North Carolina A\&T State University, Greensboro, NC, USA \\ ${ }^{2}$ Division of Atmospheric Sciences, Desert Research Institute, Reno, NV, USA \\ ${ }^{3}$ Department of Physics, North Carolina A\&T State University, Greensboro, NC, USA
}

Correspondence should be addressed to Stephany M. Taylor; staylor@aggies.ncat.edu

Received 25 February 2017; Accepted 17 May 2017; Published 24 October 2017

Academic Editor: Helena A. Flocas

Copyright (C) 2017 Stephany M. Taylor et al. This is an open access article distributed under the Creative Commons Attribution License, which permits unrestricted use, distribution, and reproduction in any medium, provided the original work is properly cited.

\begin{abstract}
This study investigates the synoptic/mesoscale dynamics responsible for an unusually heavy southern US snowstorm that occurred on February 11-12, 2010, using reanalysis, observations, and numerical simulations. This record breaking snowfall event represents an example of multiple upper level and low-level jets (LLJs) and their accompanying baroclinic zones. The analysis reveals the following synoptic scale processes as significant contributors: (1) upper level jet splitting and merging, (2) advection of cold arctic air at low levels by a large anticyclone, and (3) an incoming upper level shortwave trough. In addition to the synoptic scale processes, the following mesoscale features played a major role in this snowstorm event: coexisting potential (convective) instability and conditional symmetric instability, terrain blocking, and a double LLJ development process. Sensitivity experiments including (1) limiting the orographic effects of elevated plateau in Texas and the Sierra Madre Mountains in Mexico by reducing the terrain height to 225 meters, (2) the microphysics/latent heating effects, and (3) surface fluxes on the development and intensity of the snowstorm were also conducted by turning these options off in the numerical model. Of all three experiments, the surface flux experiment displays the least amount of influence on the developing frozen precipitation bands.
\end{abstract}

\section{Introduction}

During February 11-12, 2010, a snowfall event broke many records across the southern regions of the US. According to the National Weather Service (NWS) forecast office in Jackson, Mississippi (JAN), some areas received up to 8 inches $(20 \mathrm{~cm})$ of snow. This was the second largest February snowfall event and the tenth overall largest snowfall event on record for this region. This event was ranked as the seventh all-time snowfall event by the Shreveport, Louisiana NWS (SHV) forecast office. Additional records were broken as far west as north central Texas. The Dallas Fort-Worth (FWD) area received the greatest all-time calendar day snowfall of 11.2 inches $(28.45 \mathrm{~cm})$, the record daily maximum snowfall for February 11, the greatest all-time 24-hour snowfall of 12.5 inches $(31.75 \mathrm{~cm})$, and the record 24-hour snowfall in February according to the FWD NWS forecast office. Because of the rare nature of heavy southern snowfall events ( $>6$ inches or $>15.24 \mathrm{~cm}$ ), previous studies on this problem are very hard to find. Mote et al. [1] compiled a climatological analysis that examined heavy snowstorms in the southeastern US between January 1, 1949, and December, 31, 1992. They considered a heavy snowfall event to be at least a $10 \mathrm{~cm}(\sim 4$ inches) daily snowfall total for at least 50 stations within the study area. The study area includes the following states: Virginia, North Carolina, South Carolina, Tennessee, Georgia, Alabama, and Mississippi. A total of eighteen snowstorms were examined to find the common synoptic scale features for these heavy snowfall events. The analysis was completed in four steps: (1) identifying the individual events, (2) determining the time of initiation of snowfall, (3) constructing 12 hourly synoptic scale composites of observed analyses from 72 hours prior to 48 hours after the initiation time, and (4) discussion of significant features. Four key features were then identified: (1) cyclogenesis in the Gulf of Mexico, (2) an anticyclone advecting cold arctic air into the region, (3) an upper level 
shortwave trough approaching the region and (4) a lowlevel jet (LLJ) in advance of the trough. These common features will be examined in our case study analysis using observations, reanalysis data and numerical modeling.

Hunter et al. [2] identified seven winter storms with heavy frozen precipitation from 1994 to 1997 in the southeast US. Some similarities in each case include: (1) an upper level wind maximum located east of $100^{\circ} \mathrm{W}$ and originating near $30^{\circ} \mathrm{N}$ and (2) a $300 \mathrm{hPa}$ trough axis which migrates into eastern Texas and well into the Gulf of Mexico. Approximately six of the seven cases had jet splitting patterns, meaning the polar jet (PJ) had distinct northern and southern branches. Five of the six cases with a split flow pattern merged into a single jet prior to the end of the precipitation event. They speculated that the southern branch of the jet was very instrumental in the development of frozen precipitation. The upper level flow features, including jets and troughs, will be investigated for the February 11-12, 2010, Deep South Snowstorm event.

Probably the most widely studied snowstorm in the US that affected relatively low latitude regions was the Presidents' Day snowstorm of February 1979 that produced record snowfalls in the central Appalachian piedmont and midAtlantic region. In many ways, the extensive body of literature on this event can serve as a guide to examine similar signals in other major low latitude snowfall events such as the event analyzed in this manuscript. The first of many studies on this event examined the role of coastal frontogenesis in the early stage of the storm in which Bosart [3] demonstrated that a large and extraordinarily cold arctic anticyclone propagated far equatorward along the east coast representing a classic cold air damming episode into the leeside of the southern Appalachians as far south as Georgia. The cold air and favorable kinematics combined to produce a vigorous coastal front along the southeastern and mid-Atlantic coastal regions that served as the focal point for southeastern coastal cyclone development. Following the publication of this manuscript, Uccellini et al. [4-6] and Whitaker et al. [7] published a sequence of manuscripts that focused on the role of jet streaks and the interaction of the streaks with the coastal front and a subsequent tropopause folding event that produced a multistage evolution and intensification of this cyclone. They employed primarily upper air observational analyses and mesoscale numerical simulation studies to diagnose key multiscale processes.

There were 3 key processes found among these prior studies: (1) the role of diabatic heating accompanying the southeastern coastal front in forcing unbalanced and divergent flow in the accelerating exit region of a subtropical jet streak, (2) the synergistic interaction between the low-level jet forced by (1) and surface sensible heat flux as well as condensational heating above the coastal front and interior coastal plain in enhancing the ascent, pressure falls, and incipient cyclogenesis along the southern part of the mid-Atlantic coast, and (3) the eventual intensification of this low pressure system into an intense oceanic cyclone as the upstream polar jet streak and its stratospheric isentropic potential vorticity (IPV) interact with the developing cyclone due to the processes in (2) and subsequently create a much more powerful coastal cyclone. It is germane to point out that prior to the most rapid offshore cyclogenesis, record snowfalls were observed from western North Carolina to southern New Jersey within the cold air damming region. Similar to these Presidents' Day event analyses, Uccellini and Kocin [8] and Kocin et al. [9] both performed analyses of multilevel explosively developing coastal storms in the same region. Uccellini and Kocin [8] diagnosed the importance of the phasing of transverse circulations in both the polar and subtropical jet streaks in proximity to low-level coastal fronts in cyclone development.

All of these studies strongly imply that the synergistic interaction between upper level jet streaks and low-level baroclinic zones in the presence of prolonged diabatic heating are essential for major snowfall events at relatively low latitudes. This is facilitated by the blocking of very cold polar/arctic air masses by a terrain barrier and its effect on the subsequent enhancement of the low-level frontal zone. They also substantiate the fact that the most rapidly developing period of cyclogenesis is not necessarily the key period for the most extreme snowfall accumulations at relatively low latitude locations. Our case study will involve diagnosis of the multiscale processes responsible for the development of the heavy southern snowfall event in the lower Mississippi River Valley, where little in-depth multiscale studies have been performed. In particular, the precyclogenetic period will be the focus of a multiscale analysis employing observations, reanalysis data, and numerical simulations.

In Section 2, we will describe the methodologies used to diagnose the structure of the atmosphere preceding and resulting in this event. Section 3 will focus on a multiscale observational analysis. Section 4 will present the numerically simulated results of the control experiment and its insights into the significant stages of the evolving snowstorm as well as the sensitivity experiments performed to diagnose the impacts of the terrain, microphysics/latent heating, and surface heat/moisture fluxes on the features of the evolving snowstorm. Lastly, the summary and closing remarks are in Section 5.

\section{Methodology}

The National Centers for Environmental Prediction (NCEP) North American Regional Reanalysis (NARR) (Mesinger et al. [10]) are utilized to provide an upper level synoptic overview of the precursor state of this evolving event. Additionally standard meteograms, Skew-T diagrams, radar, and precipitation observations from Plymouth State Weather Center [11] were used as well as National Oceanic and Atmospheric Administration (NOAA) profiler network [12] data which was decommissioned in 2014. The Weather Research and Forecasting (WRF) model version 3.4 is used for the numerical simulation component of this analysis (Skamarock et al. [13]). The 6-hourly Global Forecast System (GFS) analysis data at $0.5^{\circ}$ horizontal resolution with fixed sea surface temperatures is used to initialize the model. The model simulates a 4.5 day period initialized at 1200 UTC 9 February 2010 and run through 0000 UTC 14 February 2010. It is integrated in a three-domain nest configuration shown in Figure 1(a). The configuration consists of a 36,12 , and $4 \mathrm{~km}$ domain grid with one-way nesting. The model employs 35 vertical levels from 


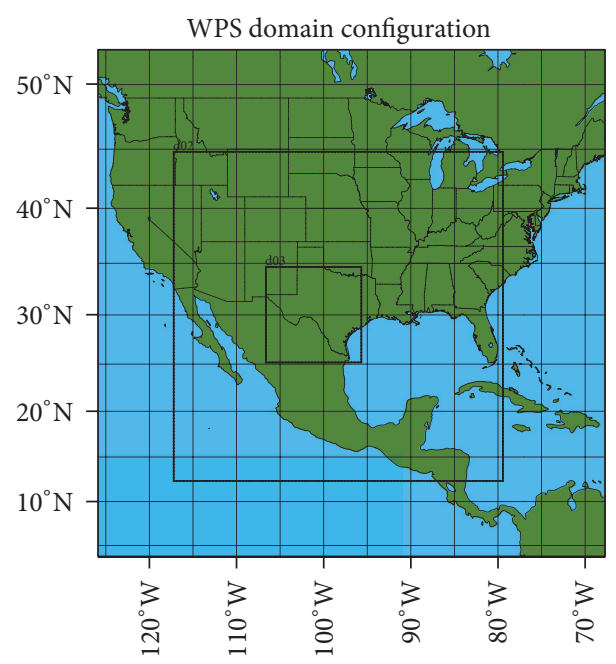

(a)

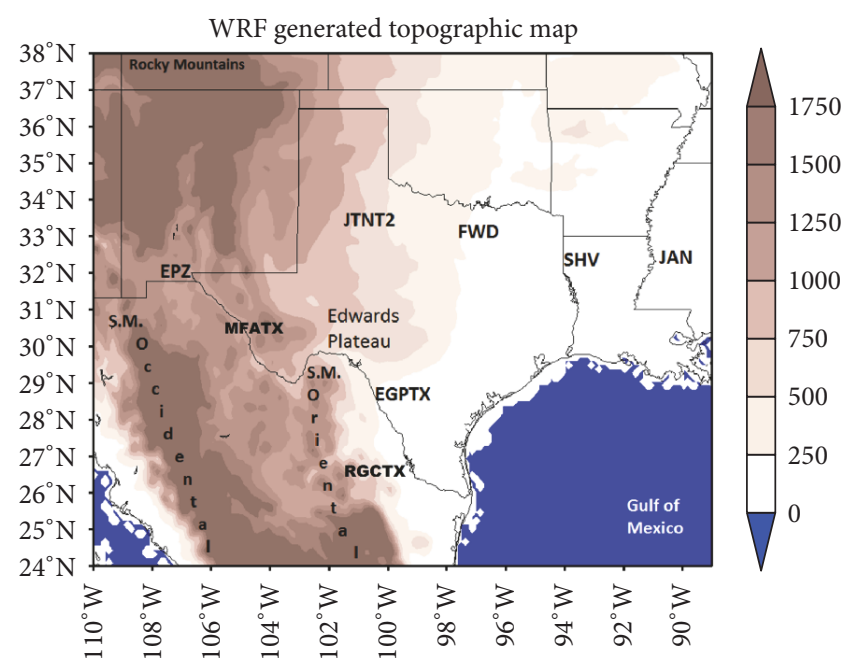

(b)

FIGURE 1: (a) Three nested WRF domain grid (36, 12, and $4 \mathrm{~km}$ resolution) and (b) WRF generated topography (m) map from the $12 \mathrm{~km}$ domain with geographical site locations over the area of interest included.

the surface to the model top of $100 \mathrm{hPa}$. The output images were created using the Grid Analysis and Display System (GrADS).

The following physics parameterization schemes were utilized for the simulations: Rapid Radiative Transfer Model (RRTM) longwave radiation (Mlawer et al. [14]), Dudhia shortwave radiation (Dudhia [15]), New Thompson microphysics scheme (Thompson et al. [16]), Betts-Miller-Janjić cumulus scheme (Betts [17]; Betts and Miller [18]; Janjić [19]) (at 36 and $12 \mathrm{~km}$ only), Mellor-Yamada-Janjić planetary boundary layer scheme (Mellor and Yamada [20, 21] and Janjić [22]), Noah Land Surface physics (Chen and Dudhia [23] and Ek et al. [24]), and United States Geological Survey (USGS) land use data (Loveland et al. [25]). Four numerical experiments were performed: (1) a control simulation as outlined above using standard envelope terrain, (2) a reduced terrain height simulation with the higher level terrain of the Sierra Madre Mountains in Mexico and elevated plateau in Texas set to 225 meters in all three WRF domains with smoothing applied everywhere, (3) the microphysics heating (no_mp_heating = 1) which is turned off, and (4) surface flux (isfflx $=0$ ) which is set to zero. The second, third, and fourth experiments were designed to test how each parameter affects the evolution of the circulation features and the intensity of the snowstorm. In the reduced terrain experiment, 225 meter height was chosen because it is approximately the average height of the elevated plateau over central Texas. For the control experiment, a comparison between the WRF model output and observational data (not shown) was done to ensure that the simulation results were close enough to accurately depict the observed environment.

\section{Observational Overview}

3.1. Snowfall Distribution and Banded Precipitation Evolution. Before describing the snowfall distribution totals and the

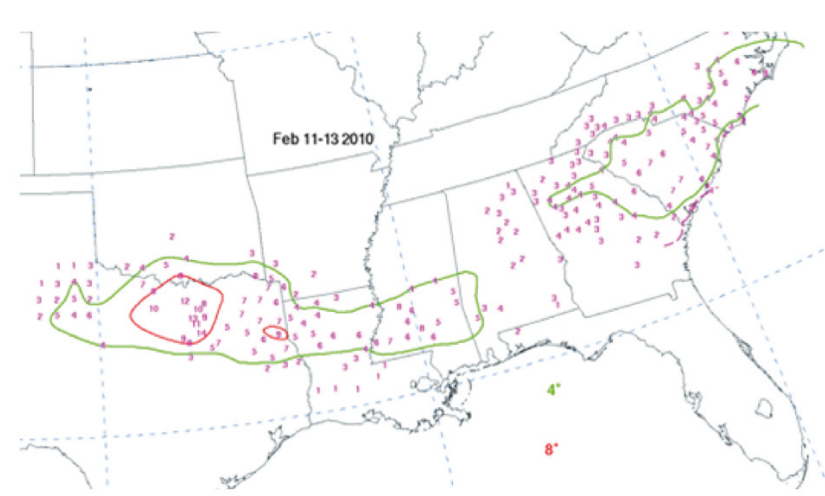

FIGURE 2: Snowfall accumulation totals (in inches), February 11-13, 2010, from WPC NCEP NOAA.

evolution of banded precipitation, we will first introduce the topography over the area of interest. Figure 1(b) is a WRF generated topographic map over this area with geographical site locations included. The mountainous terrain of the Sierra Madre Mountains in Mexico and the elevated plateau in Texas become important factors in the intensity of this snowstorm, which will be discussed later in further detail. Figure 2 depicts the total snowfall distribution by the Weather Prediction Center [26] during February 11-13, 2010, across much of the southern US. Our focus will be on the first two days of this period from Texas to Mississippi, where most of the record breaking snowfall occurred prior to the development of cyclogenesis in the Gulf of Mexico. Surface meteograms from Plymouth State Weather Center (not shown) were utilized to help determine the timing of the snowfall. Lightto-moderate and occasionally heavy snowfall occurs during the early morning through afternoon on February 11 at FWD, Texas. Snowfall arrives in northwestern Louisiana (SHV) overnight into the early morning on February 12 and in south 
central Mississippi (JAN) during the early morning through late afternoon on February 12. At each location snowfall lasts $\sim 18$ hours, with a total distance traversed by the precipitation event between FWD, Texas, and JAN, Mississippi, of $>600 \mathrm{~km}$ in less than 24 hours resulting in $>6$ inches $(>15.24 \mathrm{~cm})$ of snow accumulations.

The following radar images from Plymouth State Weather Center [11] are utilized to help describe the key precipitation structures and locations. Figure 3 displays the three hourly evolution of the precipitation bands from 0615 to 2115 UTC 11 February 2010. A track of small precipitation clusters, associated with an incoming shortwave trough, moves across Arizona and New Mexico into Texas in Figure 3(a). Equatorward, over south central and southeastern Texas stretching into Louisiana, lies a separate and lighter swath of precipitation. Over the next three hours, a heavy westeast oriented precipitation band extends across northern Texas and an equatorward band (heavier than before in Figure 3(a)) stretches from southeastern Texas into Louisiana in Figure 3(b). Between 1215 and 1515 UTC 11 February the precipitation structures turn from a west-east orientation to a southwest-northeast orientation in Figures 3(c)-3(d). The poleward precipitation band is associated with snowfall while the equatorward band is mixed precipitation, but mostly rainfall due to warmer temperatures. Radar imagery shows the precipitation bands beginning to merge closer together as they propagate further east in Figures 3(e) and 3(f).

3.2. Presnowfall Circulation Structure. This section analyzes the temporal and spatial details that explain the synoptic scale sequence of events leading to the extreme southern snowfall. These conditions are diagnosed from both synoptic scale reanalysis data and observations. Figure 4 depicts the $300 \mathrm{hPa}$ vector wind from NARR prior to the initiation of significant snowfall in Texas on February 9 and 10. Figure 4(a) displays a jet streak $>80 \mathrm{~m} \mathrm{~s}^{-1}$ over the Pacific Ocean between $175^{\circ} \mathrm{W}$ and $155^{\circ} \mathrm{W}$. Slightly east of $150^{\circ} \mathrm{W}$, the jet streak splits into distinct poleward and equatorward branches that merge again near $125^{\circ} \mathrm{W}$ over Baja California and northern Mexico. The predominantly westerly wind speed of the merged upper level jets is $>70 \mathrm{~m} \mathrm{~s}^{-1}$ over northern Mexico into south central Texas. Figure 4(b) shows that the jet streak over the Pacific Ocean decelerates as it moved further east between $165^{\circ} \mathrm{W}$ and $145^{\circ} \mathrm{W}$. Although the jet streak is much weaker, there is still split flow into distinct northern and southern branches to the east of the jet streak and converge over both Baja California and northern Mexico. Between February 9 (Figure 4(a)) and February 10 (Figure 4(b)), this confluence zone accelerates and changes from a predominately westerly to a south westerly wind flow (near Baja California, northern Mexico into Texas) while the jet streak over the Pacific Ocean decreases in wind speed over this 24-hour period. Thus, by February 10, increasing southwesterly flow above the northwestern Mexican coast can organize mass adjustments upstream of the west Texas and New Mexico locations of early precipitation on February 11.

Figure 5 denotes sea level pressure and surface temperature from Plymouth State Weather Center [11] on 0000 and 1200 UTC 10 February. In Figure 5(a), the trough covering the
California and Nevada border lies poleward of this accelerating jet in Figure 4(b). A deep anticyclone is also displayed, covering the Great Plains and stretching from Canada well into the Gulf of Mexico. The tightly packed isobars over the Sierra Madre Mountains in Mexico spanning northward over the elevated plateau of western Texas, as well as west of the Appalachian Mountains over the Mississippi River Valley represent the steep temperature gradient associated with an arctic air stream being blocked/dammed along the higher leveled terrain features in Figure 5(b). The low pressure system south of the Great Lakes in Figure 5(a) is responsible for the blizzard of February 9-10, 2010, that dropped up to 20 inches $(50.8 \mathrm{~cm})$ of snow over the eastern coastal states. Figure 5(c) shows the high pressure system almost stationary, moving slowly eastward which allows abundant amounts of cold, arctic air to penetrate the Gulf coastal states. Figure 5(d) illustrates how the $0^{\circ} \mathrm{C}(273.15 \mathrm{~K})$ temperature contour has moved southward along the southern edge of Gulf coastal states (e.g., Louisiana, Mississippi, and Alabama). A 12-hour difference in this near stationary high pressure system in Figures 5(a) and 5(c) results in a continuous arctic airstream that brings freezing temperatures to the southern states. Cold pockets of air can be seen building up against the terrain in northern Mexico in Figure 5(b) and even more dramatically 12 hours later in Figure 5(d).

Figure 6 depicts the 500 and $1000 \mathrm{hPa}$ geopotential height, wind speed, and direction from NARR on 0000 and 1200 UTC 10 February as well as 0000 UTC 11 February. Figure 6(a) displays evidence of three modes of circulation in the poleward and equatorward branches of flow. The poleward branch contains vortices or cutoff lows over the California coast and south of the Great Lakes. The equatorward branch contains an extensive zonally elongated jet streak across the subtropics extending from the eastern Pacific to the western Atlantic Ocean dominating the subtropical flow. Both the upper and lower level isoheights in Figures 6(a) and 6(b) display the two cutoff lows in the poleward branch of flow, which shows that both systems are well developed. Figure 6(b) clearly illustrates the clockwise circulation around the high pressure system (seen earlier in Figure 5(a)) extending from Canada accelerating as the winds enter the Gulf of Mexico before turning northward against the higher level terrain stretching from northeastern Mexico poleward. The terrain barrier allows the cold arctic air from the near stationary surface anticyclone to remain trapped as the polar and subtropical airstreams (as seen in Figure 4) converge over the same area. Hence, each airstream (arctic, polar, and subtropical) is ultimately on a "collision" course over the US southern plains and lower Mississippi River Valley which is beginning to occur as time progresses in Figures 6(c)-6(f). This collision is facilitated near the Sierra Madre Mountains in Mexico and the elevated plateau in Texas as cold air is funneled east of the terrain barrier and the airflow turns towards the north in west Texas.

\subsection{Implications of the "Collision" Zone for Initiation of} Snowfall. Skew-T diagrams from Santa Teresa, New Mexico (EPZ), and FWD, Texas, along with NOAA Profilers from Jayton, Texas (JTNT2), Eagle Pass, Texas (EGPTX), Marfa, Texas (MFATX), and Rio Grande City, Texas (RGCTX), 


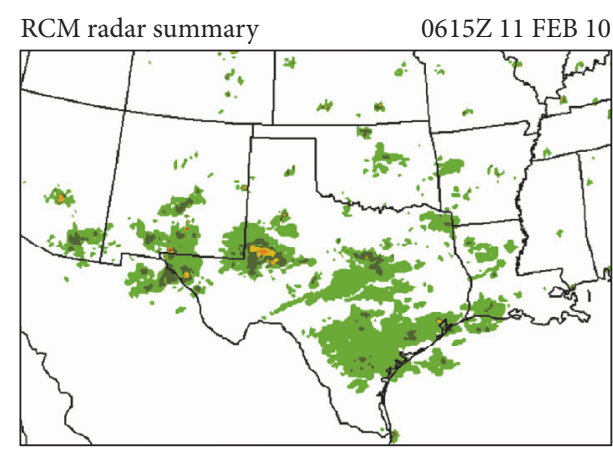

Tlymouth State

Intensities (Dbz):

\begin{tabular}{|c|}
\hline 20 \\
\hline - 30 \\
\hline
\end{tabular}

(a)

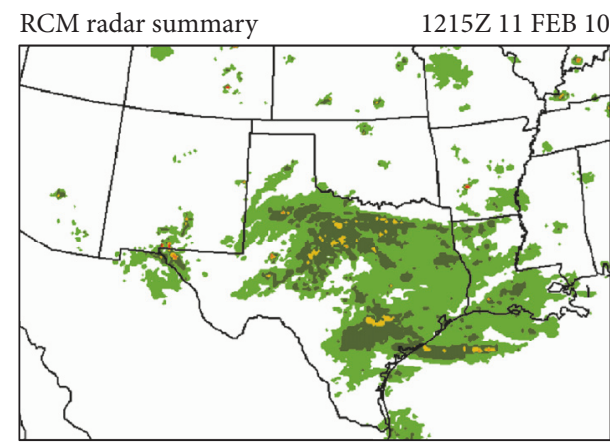

Clymouth State

Intensities (Dbz):

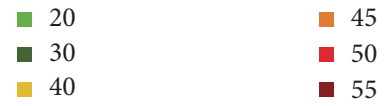

(c)

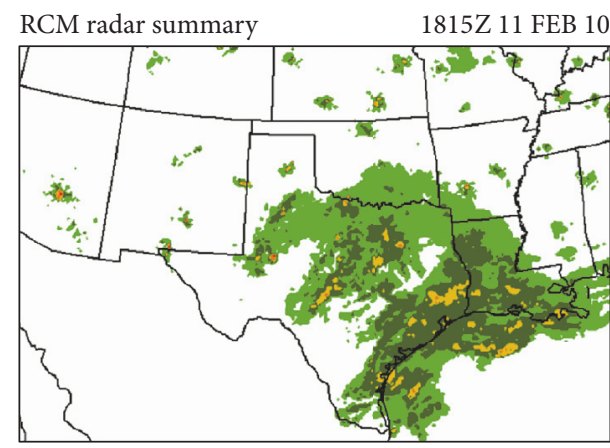

Plymouth State

Intensities (Dbz):

$\begin{array}{ll}\square 20 & \square 5 \\ \square & \square 0 \\ 30 & \square 5\end{array}$

(e)

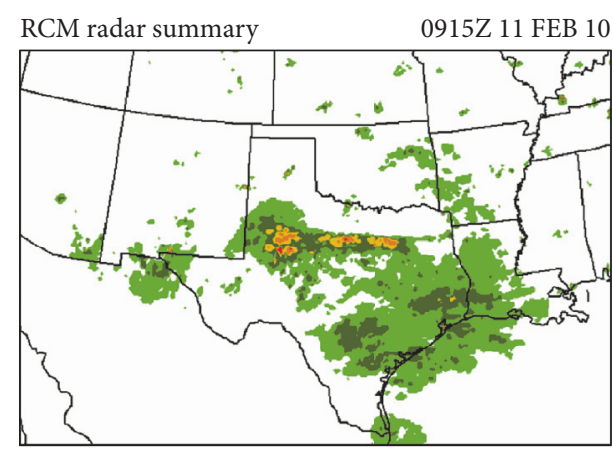

Tlymouth State

Intensities (Dbz):

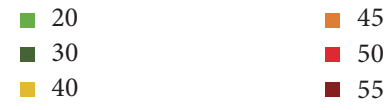

(b)

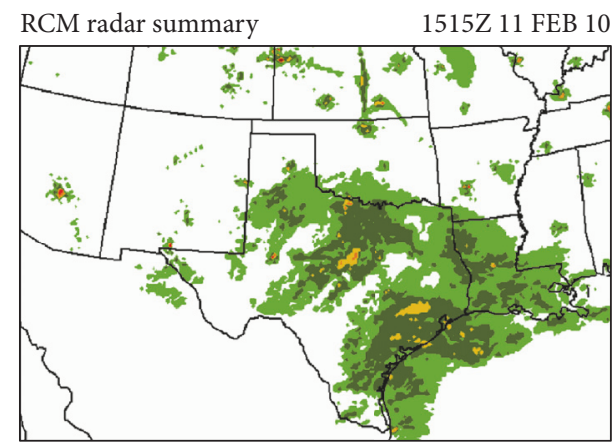

Plymouth State

Intensities (Dbz):

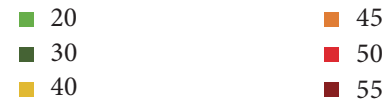

(d)

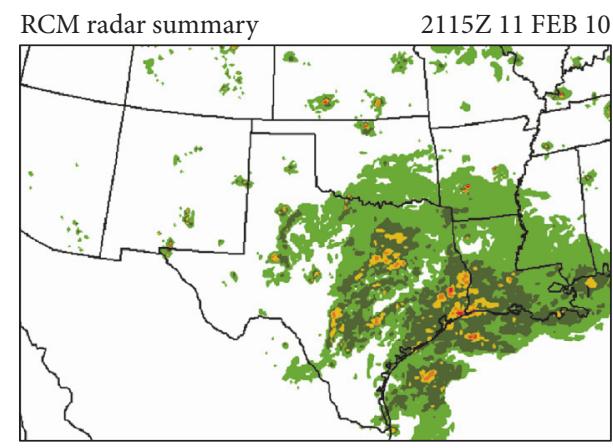

Tlymouth State

Intensities (Dbz):

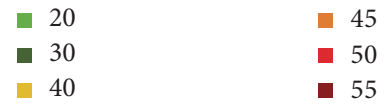

(f)

FIGURE 3: Plymouth State Weather Center radar summary (Dbz) valid at (a) 0615 UTC, (b) 0915 UTC, (c) 1215 UTC, (d) 1515 UTC (e) 1815 UTC, and (f) 2115 UTC 11 February 2010. 

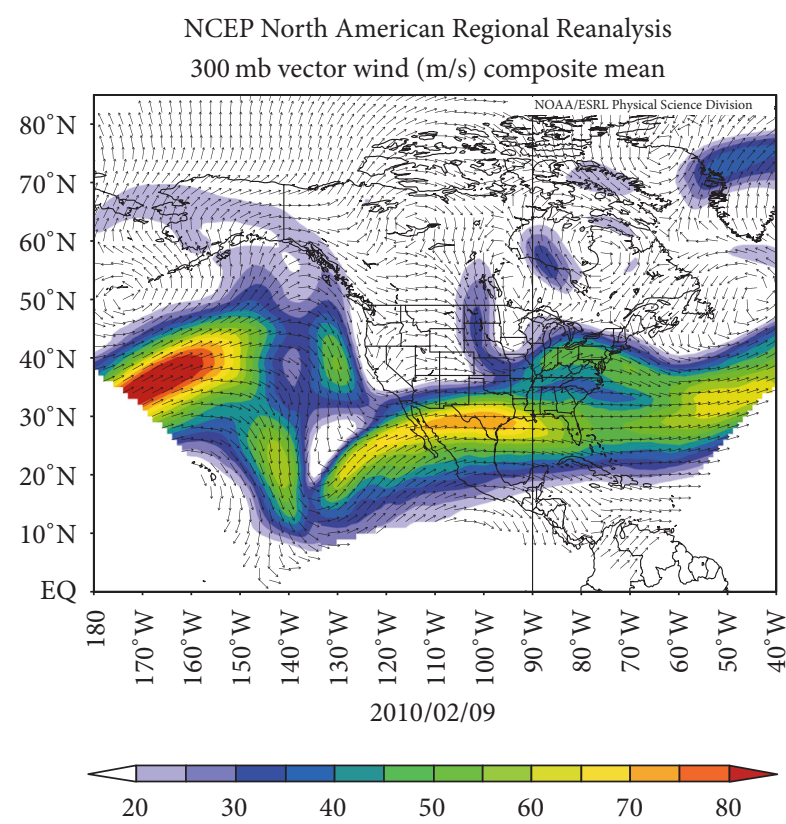

(a)
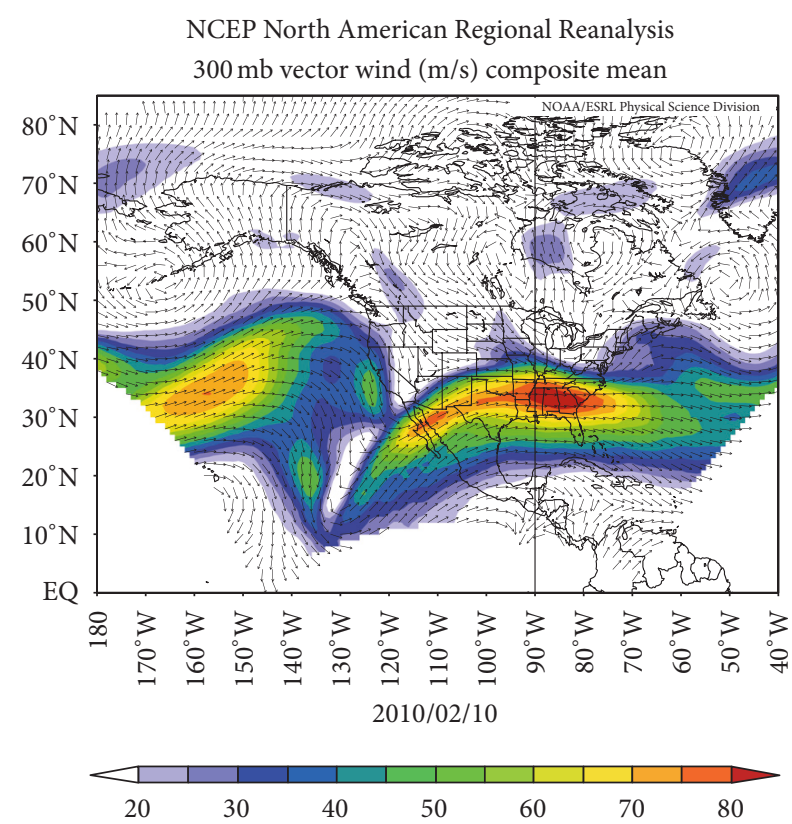

(b)

FIGURE 4: NCEP NARR 300 hPa vector wind composite mean on (a) February 9 and (b) February 10, 2010. The daily composite means are averages of 3 hourly NARR data.

were intercompared with the multilevel NARR geopotential height and wind observations for signals of the relationship between upper and lower level wind adjustments during the organization of early convective snowfall. Figures $7(a)-7(b)$ show wind flow veering with height or turning clockwise with height, which indicates warm air advection (WAA). The surface accompanies a south-southeasterly LLJ below $1 \mathrm{~km}$ which coincides with the anticyclonic wind flow (seen in the previous $1000 \mathrm{hPa}$ figure) and a southwesterly wind near $700 \mathrm{hPa}$. The Skew-T diagram for EPZ in Figure 7(a) shows a hydrolapse or significant decrease in the dewpoint near midtropospheric levels with near saturation beneath. This is an indication of potential (convective) instability (PI) or $\partial \theta_{e} / \partial z<0$, elevated above a more stable layer (Lin [27]). The LLJ between 850 and $700 \mathrm{hPa}$ veers from a south to southwest flow over the next 24 hours in Figures 7(a)-7(b), bringing an abundance of moisture as the relative humidity $(\mathrm{RH})$ more than doubles from $34.2 \%$ to $79 \%$ over this area in western Texas. Over 600 miles $(965.6 \mathrm{~km})$ east, FWD experiences shallow cold air advection (CAA) with freezing temperatures at the surface as the winds are backing with height (or winds turning counterclockwise with height) on 1200 UTC 10 February in Figure 7(c). At 1200 UTC 11 February 2010, the winds begin veering with height in Figure 7(d) as the RH increases from $41.9 \%$ to $90.7 \%$ similar to the EPZ soundings with $\mathrm{RH}$ more than doubling as the wind flows from the southwest in both the upper and lower levels. $\partial \theta_{e} / \partial z$ at EPZ (Figure 7(a)) and FWD (Figure 7(c)) in the most unstable layers are -0.00151 and $-0.000364 \mathrm{~K} \mathrm{~m}^{-1}$, respectively.

There is further analysis of (1) NOAA Profilers for the following cities: Jayton, Texas (JTNT2, Figure 8(a)), Eagle Pass, Texas, (EGPTX, Figure 8(b)), Marfa, Texas (MFATX,
Figure 9(a)), and Rio Grande City, Texas (RGCTX, Figure 9(b)), during 0600 UTC 10 February-0600 UTC 11 February that were intercompared with Skew-T diagrams as well as multilevel NARR height and winds for signals of the relationship between upper and low-level mesoscale wind adjustments and the organization of early convective snowfall. Figure 8 indicates that on February 10, low-level wind flow near the surface accompanies a south and southeasterly low-level jet below $1 \mathrm{~km}$ which coincides with the $1000 \mathrm{hPa}$ jet approaching west Texas in Figure 6 and Skew-T diagrams from EPZ in Figure 7. This jet strengthens substantially at JTNT2 (Figure 8(a)), EGPTX (Figure 8(b)), and MFATX (Figure 9(a)) between 1200 and 1800 UTC 10 February both near surface below $1 \mathrm{~km}$ and near $850 \mathrm{hPa}$. Farther south (Figure $9(\mathrm{~b})$ ), below $1 \mathrm{~km}$, is a steady easterly stream of wind flow with increasing flow speeds aloft as the winds veer with height. Aloft at $8-12 \mathrm{~km}$, below and roughly coincident with $100-200 \mathrm{hPa}$, one can see best at JTNT2 (Figure 8(a)) the increasing wind flow from the southwest during this same period as the westerlies begin to slightly weaken and the southwesterly flow arrives. The inference being that the higher frequency adjustments in the NARR, Skew-T, and profiler winds aloft are coupled to the increasing low-level jet as the column becomes wetter and more unstable.

The profilers at JTNT2 (Figure 8(a)), EGPTX (Figure 8(b)), MFATX (Figure 9(a)), and RGCTX (Figure 9(b)) indicate that after $\sim 6$ hours of flow deceleration (after 1800 UTC 10 February near $2-3 \mathrm{~km}$ or $700-850 \mathrm{hPa}$ ), a second and further southeast (i.e., at EGPTX (Figure 8(b)), MFATX (Figure 9(a)), and RGCTX (Figure 9(b)) in particular) stronger LLJ develops during 0000-0600 UTC 11 February. This second LLJ is consistent with two strong signals in the 
Plymouth State Weather Center

Sea level pressure (mb) WXP analysis for 00Z 10 Feb 10

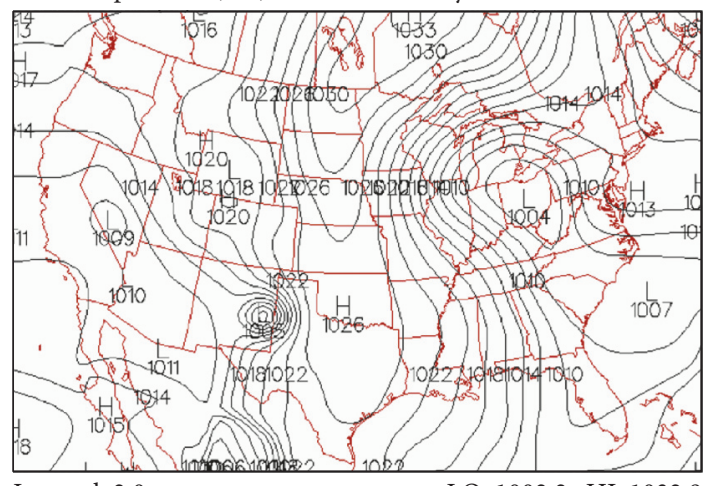

Interval: 2.0

(a)

Plymouth State Weather Center

Sea level pressure $(\mathrm{mb}) \quad$ WXP analysis for $12 \mathrm{Z} 10 \mathrm{Feb} 10$

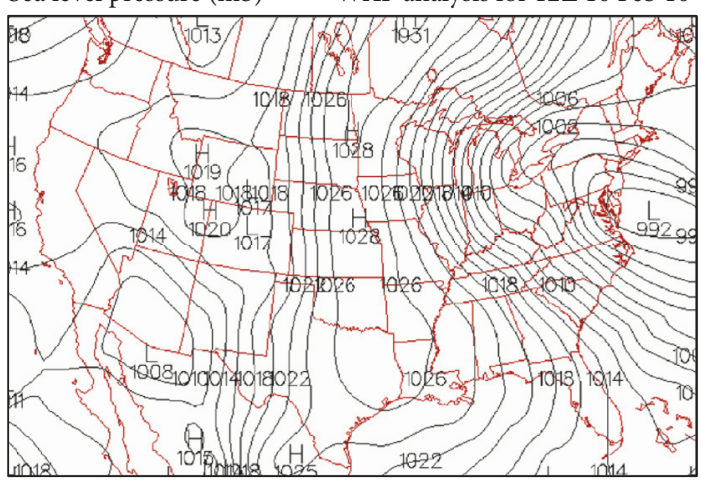

Interval: 2.0
LO: 992.0 HI: 1030.6

(c)
Tlymouth State Weather Center

Surface temperature $\left({ }^{\circ} \mathrm{C}\right) \quad$ WXP analysis for $00 \mathrm{Z} 10 \mathrm{Feb} 10$

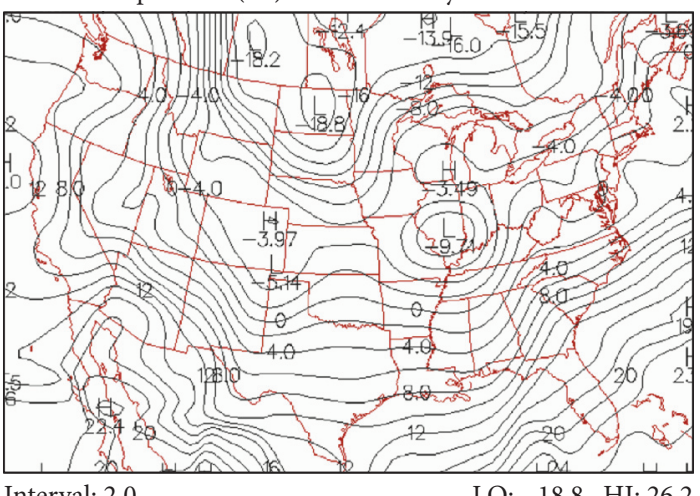

(b)

Plymouth State Weather Center

Surface temperature $\left({ }^{\circ} \mathrm{C}\right) \quad$ WXP analysis for $12 \mathrm{Z} 10 \mathrm{Feb} 10$

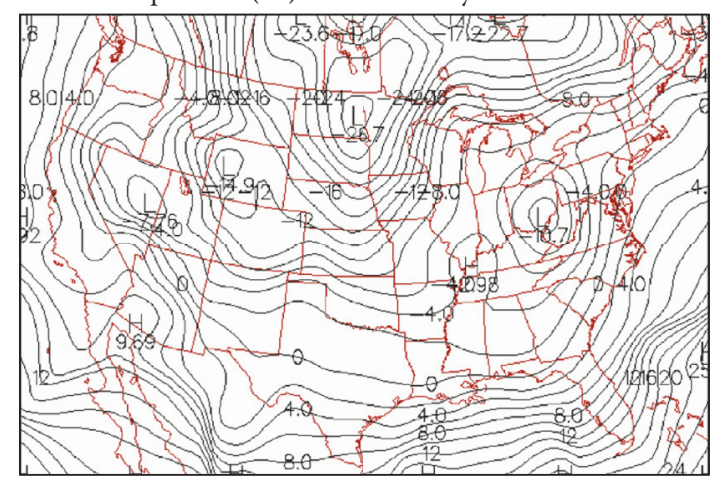

Interval: 2.0
LO: -26.7 HI: 27.3

(d)

FIGURE 5: Plymouth State Weather Center sea level pressure and surface temperature (a-b) valid for 0000 UTC 10 February and (c-d) valid for 1200 UTC 10 February 2010.

Skew-T diagrams depicted in Figures 7(c)-7(d) during 1200 UTC 10 February and 1200 UTC 11 February at FWD, Texas. The first signal between 1200 UTC 10 February and 1200 UTC 11 February is the weakening westerly wind flow of the PJ $\sim 250 \mathrm{hPa}$ as it propagates southeastwards. The second signal is the deepening of the low-level inversion in time accompanying a very strong turning of the low-level flow from $\sim 925-750 \mathrm{hPa}$ at FWD. This deepening of the inversion is coincident with both accelerations in the low-level jet evident in the profilers described above which suggests a double LLJ developmental process. One LLJ is closely coupled to the low-level baroclinic feature (i.e., the cold air damming along the Sierra Madre) and the secondary LLJ, particularly at Rio Grande City where the low-level accelerations are very strong (Figure 9(b)), represents a likely precursor feature to cyclogenesis in the Gulf of Mexico. Numerical simulation analyses will be presented in the next section to help determine the key temporal and spatial details leading to the record snowfall.

\section{Numerical Simulation Experiments}

In this section of the manuscript, we will utilize 12 and $4 \mathrm{~km}$ WRF simulations to diagnose the key stages of the snowfall event. First, we will examine the low-level flow and blocking triggered by the mountainous terrain as well as midlevel and upper level flow that is responsible for the sequence in initial organization of convection. Secondly, we will diagnose the types of convective instability over the area of interest that are responsible for the heavy precipitation bands that create the blizzard conditions prior to cyclogenesis. Lastly, we will determine the effect and/or the role of mountainous terrain, microphysics heating, and surface fluxes on these snowstorm-generating processes on subsequent Gulf of Mexico cyclogenesis. This will be achieved by analyzing sensitivity experiments that include a terrain reduction sensitivity experiment, an experiment setting the surface flux to zero, and another to cut off the microphysics heating to better diagnose their effects on the downstream 

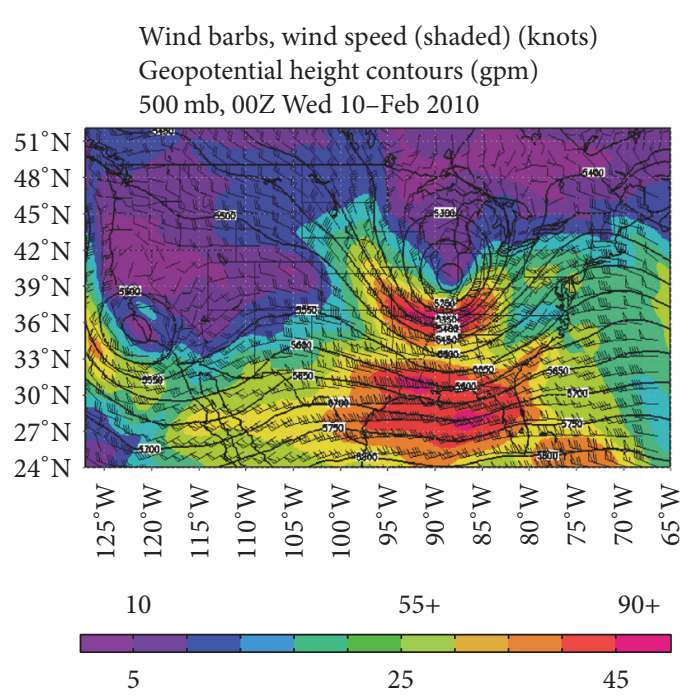

(a)

Wind Barbs, wind speed (shaded) (knots) Geopotential height contours (gpm) 500 mb, 12Z Wed 10-Feb 2010
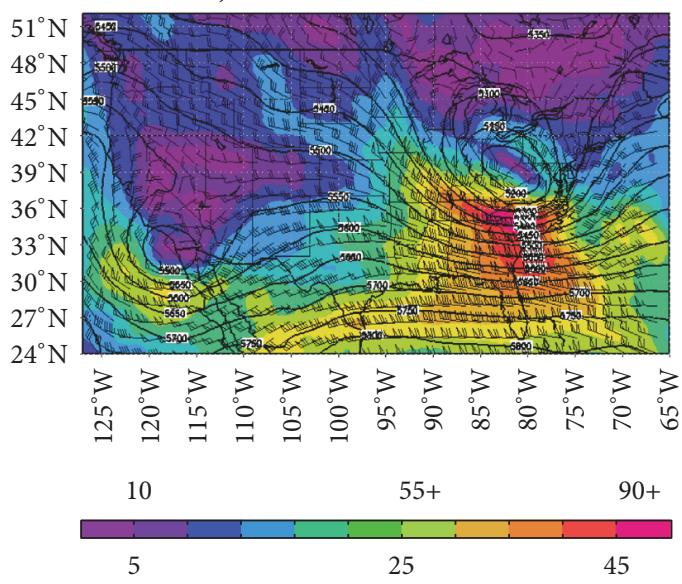

(c)

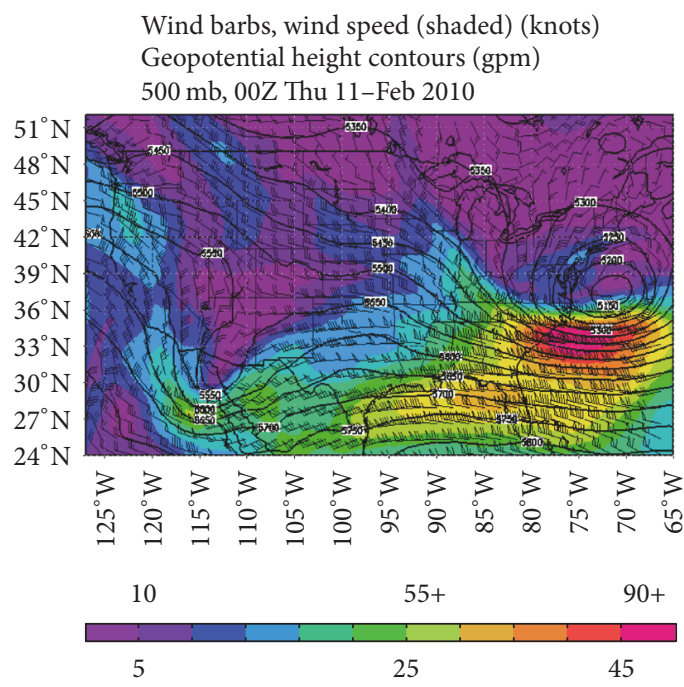

(e)

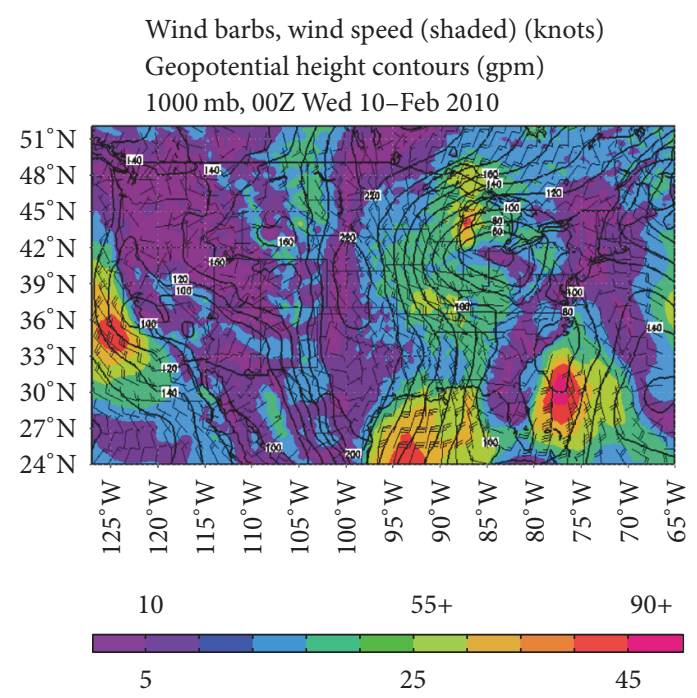

(b)

Wind barbs, wind speed (shaded) (knots) Geopotential height contours (gpm) 1000 mb, 12Z Wed 10-Feb 2010
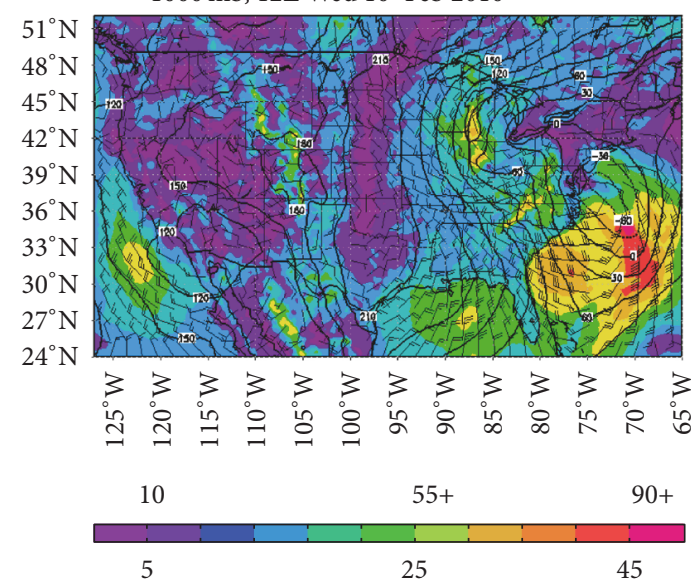

(d)

Wind barbs, wind speed (shaded) (knots) Geopotential height contours (gpm)

$1000 \mathrm{mb}, 00 \mathrm{Z}$ Thu 11-Feb 2010
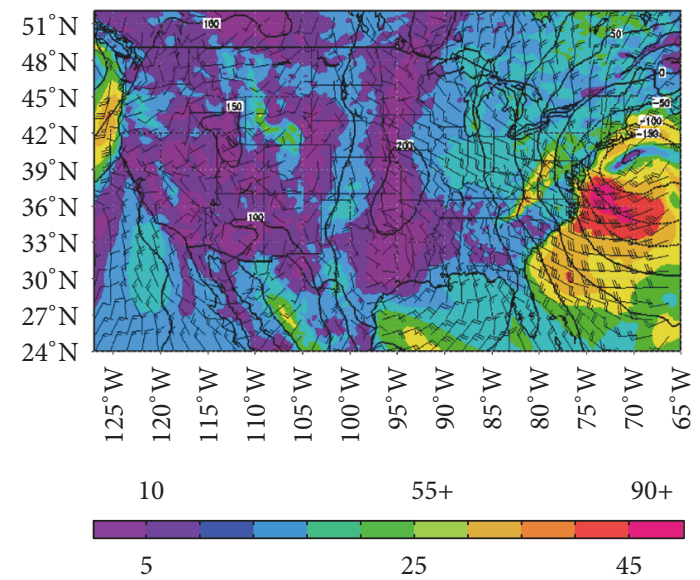

(f)

FIGURE 6: NARR 500 and $1000 \mathrm{hPa}$ geopotential height (gpm), wind barbs, and wind speed in knots (shaded) valid at (a-b) 0000 UTC 10 February, (c-d) 1200 UTC 10 February 2010, and (e-f) 0000 UTC 11 February 2010. 


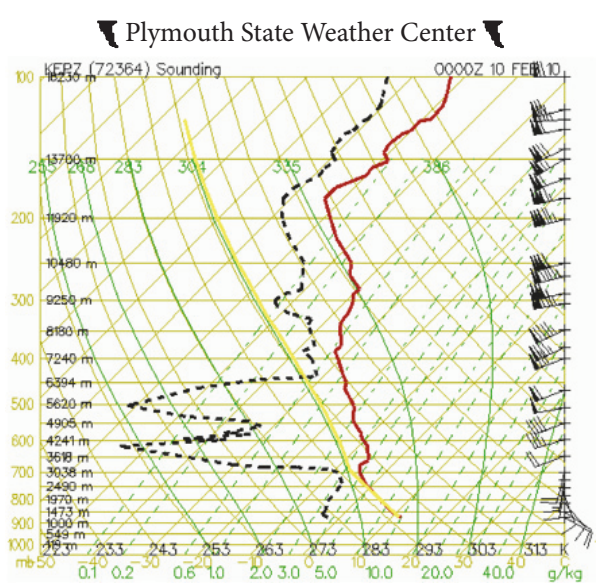

(a)

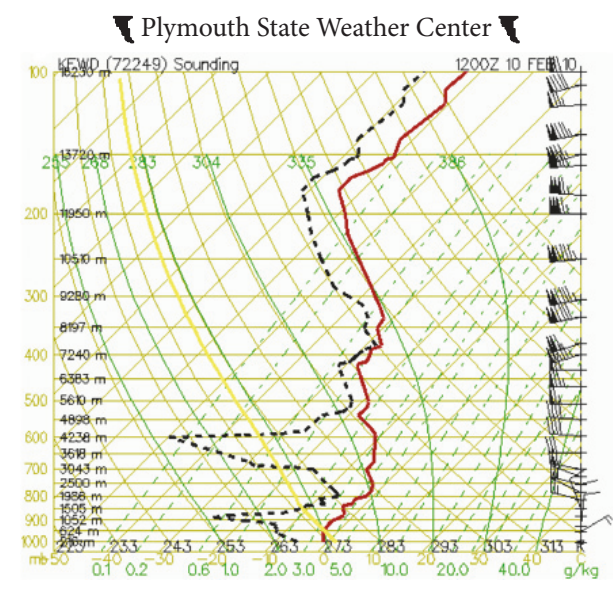

(c)

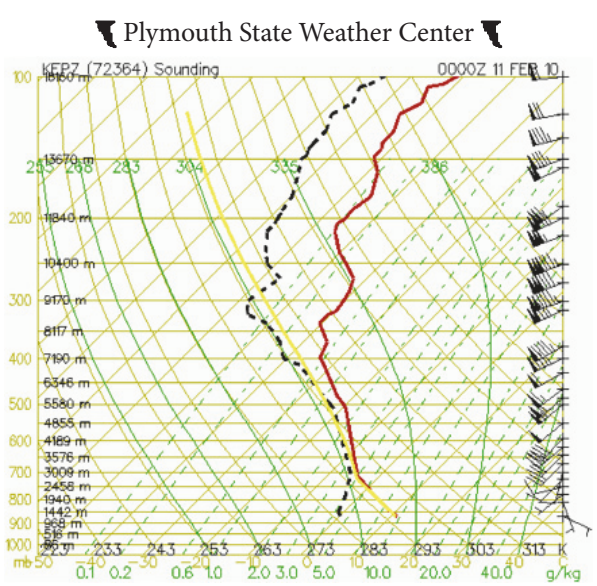

(b)

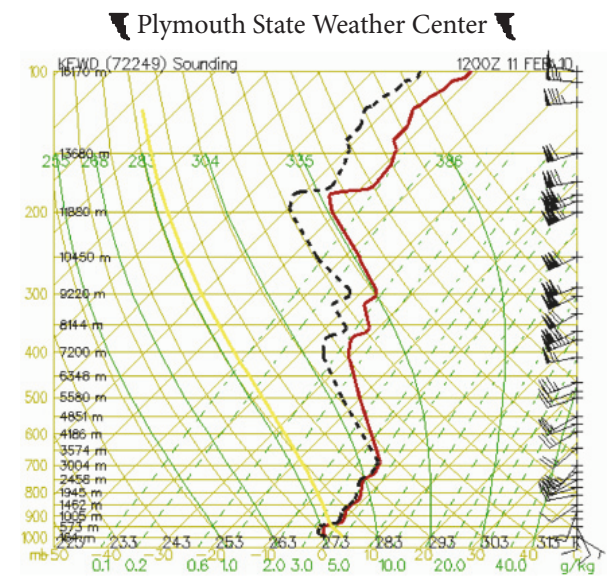

(d)

Figure 7: Plymouth State Weather Center radiosonde soundings for El Paso, Texas (EPZ) valid at (a, b) 0000 UTC 10 and 11 February and Dallas Fort-Worth, Texas (FWD), valid at (c, d) 1200 UTC 10 and 11 February 2010.

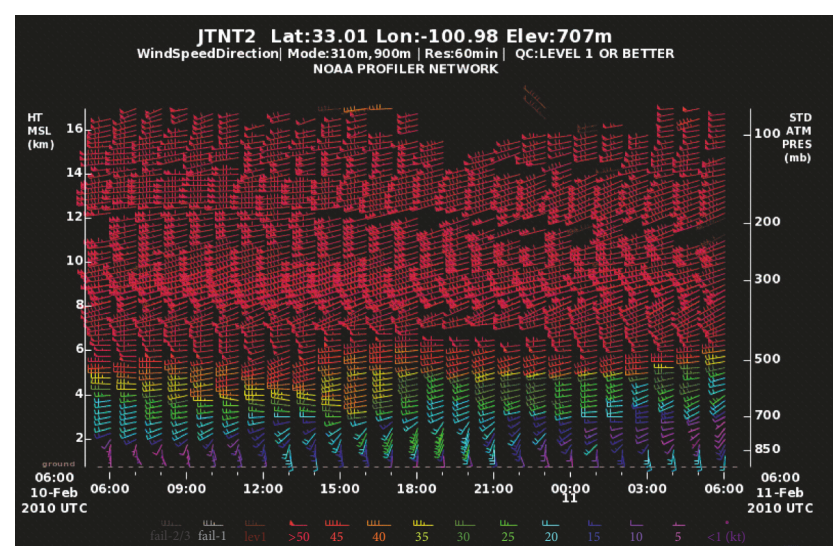

(a)

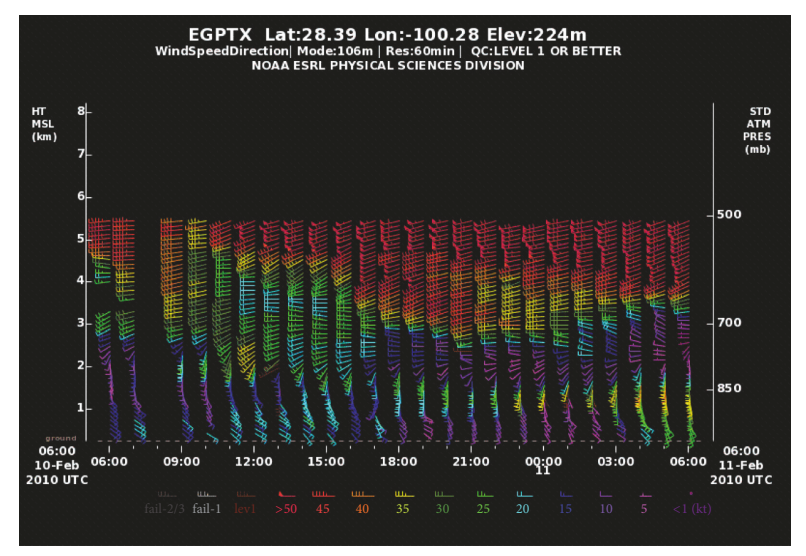

(b)

FIgURE 8: NOAA wind profilers (in knots) for (a) Jayton, Texas, and (b) Eagle Pass, Texas, valid from 0600 UTC 10 February to 0600 UTC 11 February 2010. 


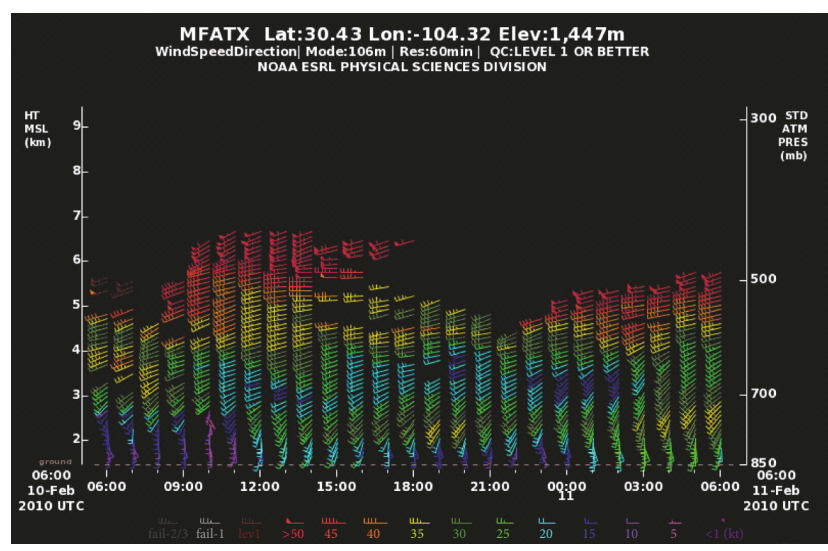

(a)

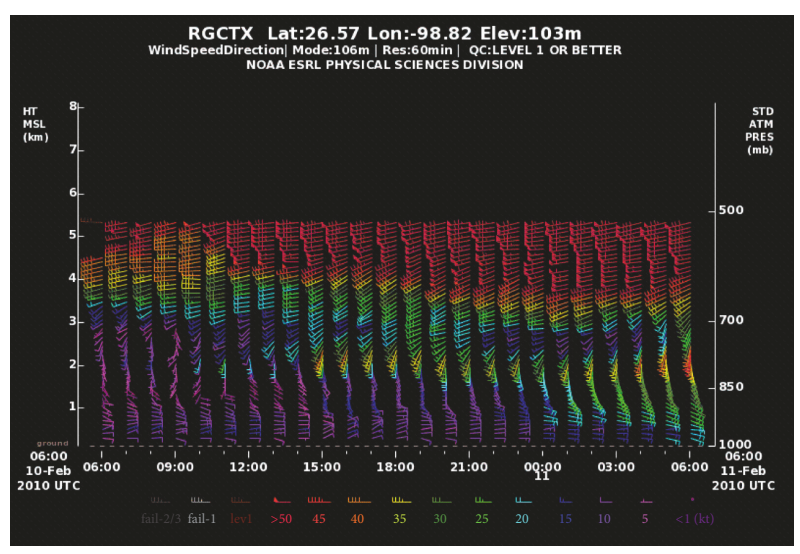

(b)

FIgURE 9: NOAA wind profilers (in knots) for (a) Marfa, Texas, and (b) Rio Grande City, Texas, valid from 0600 UTC 10 February to 0600 UTC 11 February 2010.

evolution of the key synoptic and mesoscale features that created the record snow and subsequent cyclogenesis.

\subsection{Terrain-Induced Synergistic Interactions Leading to Mul-} tiple Jet Circulations. Figure 10 depicts the $300 \mathrm{hPa}$ and $200 \mathrm{hPa}$ wind and geopotential height to show the PJ and STJ interactions directly associated with the Deep South Snowstorm at 3 hourly intervals between 0000 and 0900 UTC 11 February. Figures 10(a)-10(b) show two upper level jet streaks at the western edge of the domain, the northward (PJ) streak being the strongest spanning from Baja California northeastwards and a much weaker, southward (STJ) streak extending from northern Mexico across Marfa, Texas. On 0300 UTC 11 February in Figure 10(c), both jet streaks increase wind speeds as they continue to propagate northeastwards. However, the STJ streak speeds up to pass the PJ streak across central Texas into Louisiana in some sort of "race effect" of the previous juxtaposed position of the jet streaks just three hours before in Figure 10(a). At the $200 \mathrm{hPa}$ level both upper level jet streaks are much weaker in Figure 10(d). The STJ streak is comprised of multiple jetlets across northern Mexico into central Texas instead of one continuous streak as seen in the 300 hPa STJ streak in Figure 10(c). On 0600 UTC 11 February, the previous "race effect" of the STJ streak across Texas continues and connects to the stronger jet streak associated with the exiting Nor'easter near the east coast over the lower Mississippi River Valley in Figures 10(e)-10(f). A Nor'easter is an extratropical cyclone that causes significant damage along the east coast of the US (Davis and Dolan [28]). The STJ streak acts as a bridge to merge or connect the upper level PJ streak that it passes to the other PJ streak that it eventually catches up to in Figures 10(g)-10(h) on 0900 UTC 11 February.

Figure 11 displays mean sea level pressure (MSLP), $600 \mathrm{hPa} \mathrm{RH}$, and 540 dam contour of the $1000-500 \mathrm{hPa}$ thickness at 3 hourly intervals between 0000 and 0900 UTC 11 February. Figures 11(a)-11(d) show dominating high pressure over time over the lower Mississippi River Valley and the incoming shortwave trough as it moves across northern Mexico (similar to the observational analysis in Figure 5).
These figures also illustrate the collision zone of two moisture sources (the shortwave trough (PJ) and the atmospheric river (STJ)) over the FWD, Texas area. The cold air associated with the high pressure system can be seen north of the 540 dam thickness contour along the southern edge of the Gulf coastal states, which some forecasters use to determine the rain/snow line. In response to the more extreme low-level CAA that occurred on the previous day during 0600 UTC 10 February, the blocked flow along the terrain near $104^{\circ} \mathrm{W}$ between 28 and $36^{\circ} \mathrm{N}$ was calculated. A small Froude number flow $(\mathrm{Fr}=U / N h \ll 1.0)$ was calculated where the wind speed $U=6 \mathrm{~m} \mathrm{~s}^{-1}, N=0.36 \mathrm{~s}^{-1}$, and terrain height $(h)$ were $\sim 1300$ meters. The Edwards Plateau in Texas and southward along the Sierra Madre Mountains in Mexico acts as a barrier as the arctic air near the surface is differentially advected parallel to, diverted around, and enhanced by differential upslope flow relative to the terrain. This differential cold air advection and upslope flow/adiabatic generation of cold air create lowlevel ridging/troughing along the terrain also known as cold air damming. The pressure rises are more effective on the elevated plateau in perturbing the deep mass field relative to the thickness falls due to cooling.

Figure 12 illustrates the $850 \mathrm{hPa}$ wind and the $0^{\circ} \mathrm{C}$ $(273.15 \mathrm{~K})$ temperature contour at 3 hourly intervals between 0000 and 0900 UTC 11 February. As the trough propagates eastward on February 11 in Figure 11, it is going to eventually approach the collision zone over Texas where two different low-level baroclinic frontal systems will collide. One is the near surface arctic front impinging on the Sierra Madre Oriental Mountains in Mexico and Texas plateau; the other is polar in origin associated with the incoming shortwave trough impinging on the Sierra Madre Occidental Mountains in northern Mexico in Figures 12(a)-12(d). The LLJs of these baroclinic systems begin to converge over the mountainous terrain. The continuous eastward propagation of the upstream trough and the somewhat stagnant high pressure system over the deep south states in Figures 11(a)-11(d) are what initiate the collision of these dual LLJ systems in Figures $12(\mathrm{a})-12(\mathrm{~d})$. The freezing temperatures north of the 


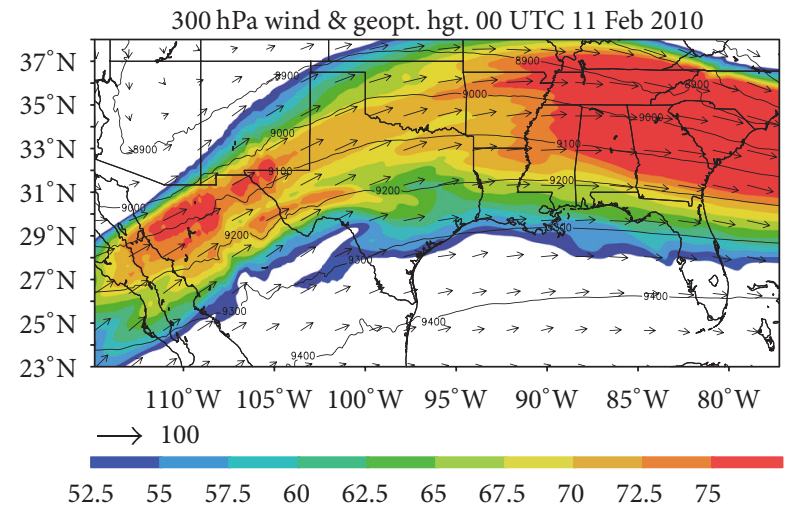

(a)
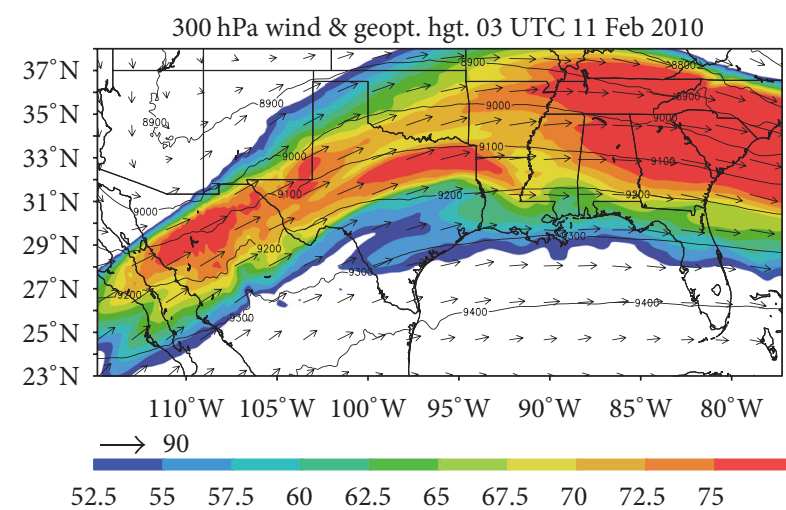

(c)

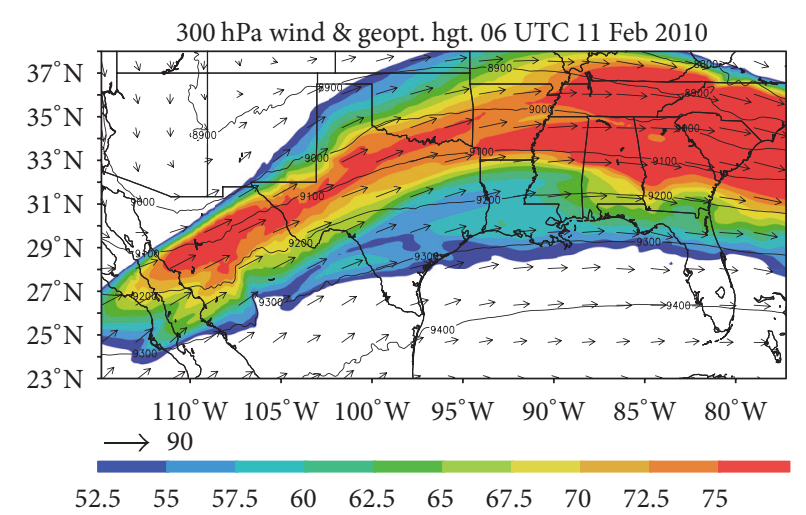

(e)

300 hPa wind \& geopt. hgt. 09 UTC 11 Feb 2010

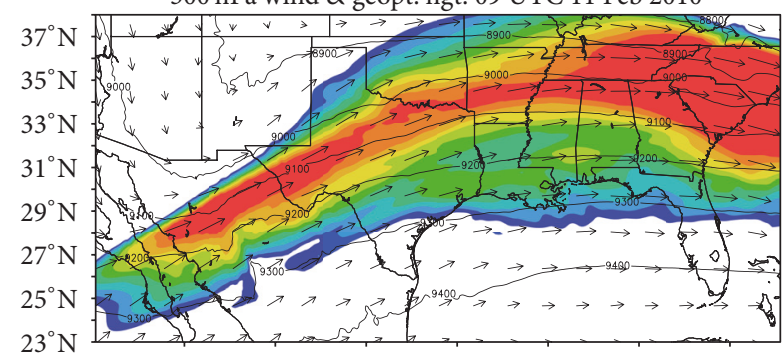

$110^{\circ} \mathrm{W} \quad 105^{\circ} \mathrm{W} \quad 100^{\circ} \mathrm{W} \quad 95^{\circ} \mathrm{W} \quad 90^{\circ} \mathrm{W} \quad 85^{\circ} \mathrm{W} \quad 80^{\circ} \mathrm{W}$ $\longrightarrow 90$

$\begin{array}{llllllllll}52.5 & 55 & 57.5 & 60 & 62.5 & 65 & 67.5 & 70 & 72.5 & 75\end{array}$

(g)

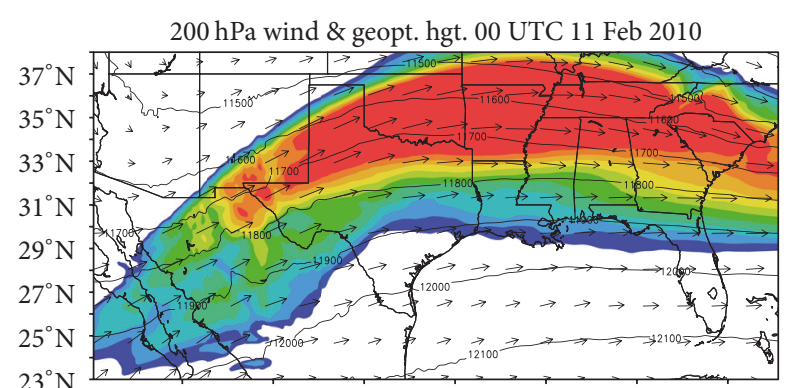

$110^{\circ} \mathrm{W} \quad 105^{\circ} \mathrm{W} \quad 100^{\circ} \mathrm{W} \quad 95^{\circ} \mathrm{W} \quad 90^{\circ} \mathrm{W} \quad 85^{\circ} \mathrm{W} \quad 80^{\circ} \mathrm{W}$ $\begin{array}{rlllllllll}\longrightarrow & 100 \\ 57.5 & 60 & 62.5 & 65 & 67.5 & 70 & 72.5 & 75 & 77.5 & 80\end{array}$

(b)

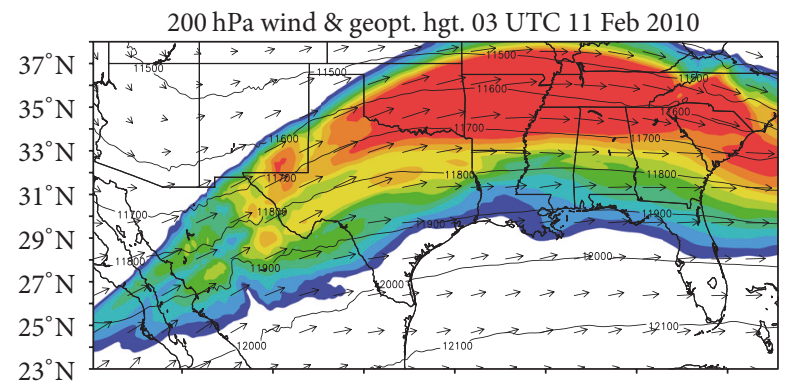

$110^{\circ} \mathrm{W} \quad 105^{\circ} \mathrm{W} \quad 100^{\circ} \mathrm{W} \quad 95^{\circ} \mathrm{W} \quad 90^{\circ} \mathrm{W} \quad 85^{\circ} \mathrm{W} \quad 80^{\circ} \mathrm{W}$ $\longrightarrow 100$

$\begin{array}{llllllllll}57.5 & 60 & 62.5 & 65 & 67.5 & 70 & 72.5 & 75 & 77.5 & 80\end{array}$

(d)

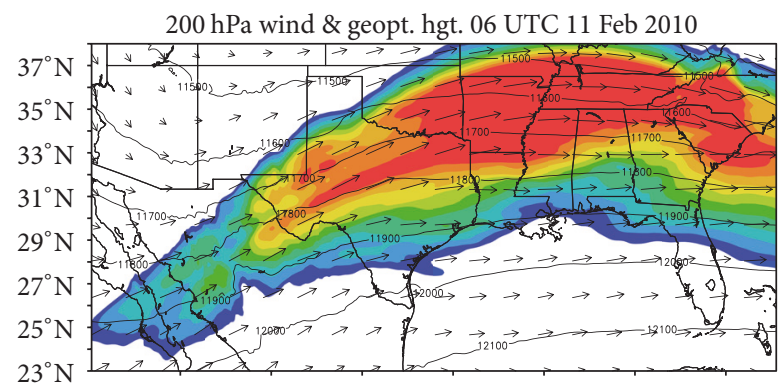

$110^{\circ} \mathrm{W} \quad 105^{\circ} \mathrm{W} \quad 100^{\circ} \mathrm{W} \quad 95^{\circ} \mathrm{W} \quad 90^{\circ} \mathrm{W} \quad 85^{\circ} \mathrm{W} \quad 80^{\circ} \mathrm{W}$ $\longrightarrow 90$

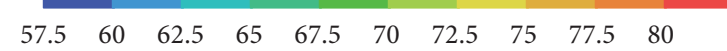

(f)

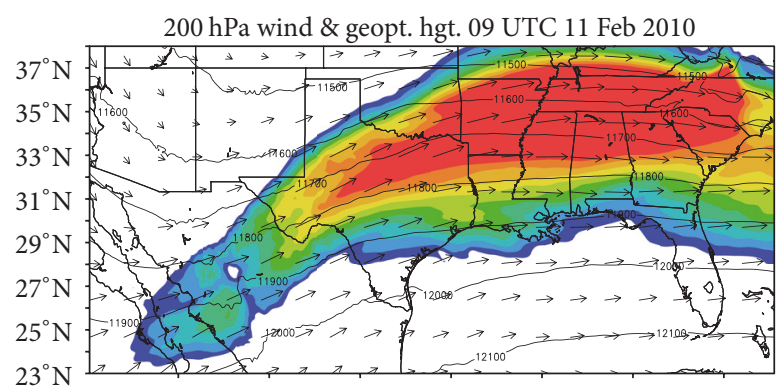

$110^{\circ} \mathrm{W} \quad 105^{\circ} \mathrm{W} \quad 100^{\circ} \mathrm{W} \quad 95^{\circ} \mathrm{W} \quad 90^{\circ} \mathrm{W} \quad 85^{\circ} \mathrm{W} \quad 80^{\circ} \mathrm{W}$ $\longrightarrow 90$

$\begin{array}{llllllllll}57.5 & 60 & 62.5 & 65 & 67.5 & 70 & 72.5 & 75 & 77.5 & 80\end{array}$

(h)

FIgURE 10: Simulated $(12 \mathrm{~km}) 300 \mathrm{hPa}$ wind $\left(\mathrm{m} \mathrm{s}^{-1}\right)$ and geopotential height in gpm (a, c, e, and g) and $200 \mathrm{hPa}$ wind ( $\left.\mathrm{m} \mathrm{s}^{-1}\right)$ and geopotential height in gpm (b, d, f, and h) on 0000, 0300, 0600, and 0900 UTC 11 February 2010. 


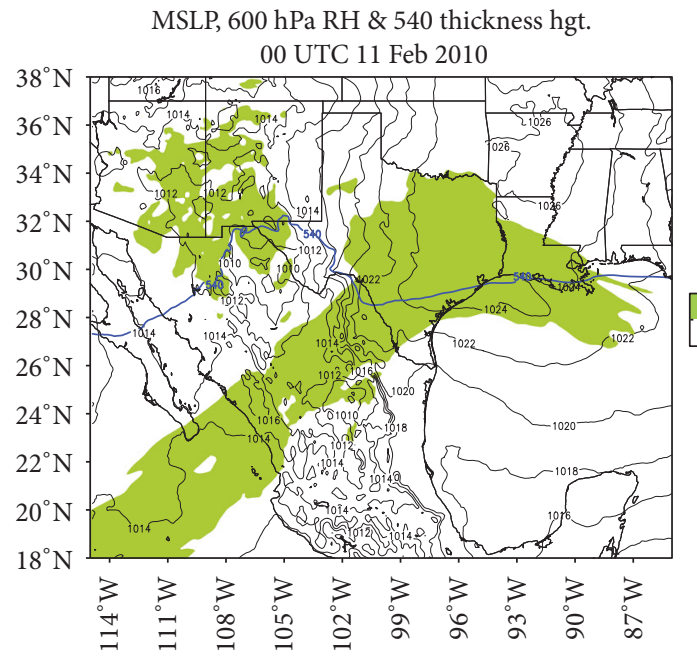

(a)

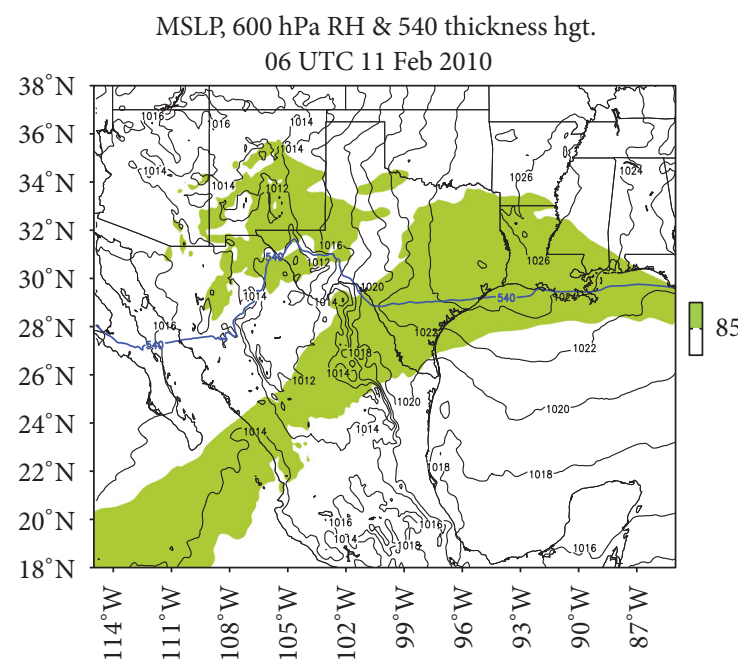

(c)

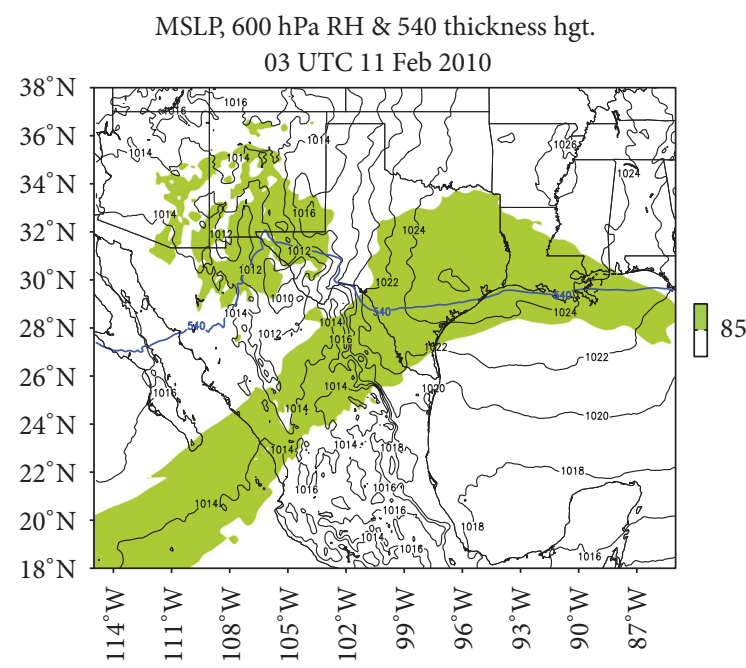

(b)

MSLP, 600 hPa RH \& 540 thickness hgt. 09 UTC 11 Feb 2010

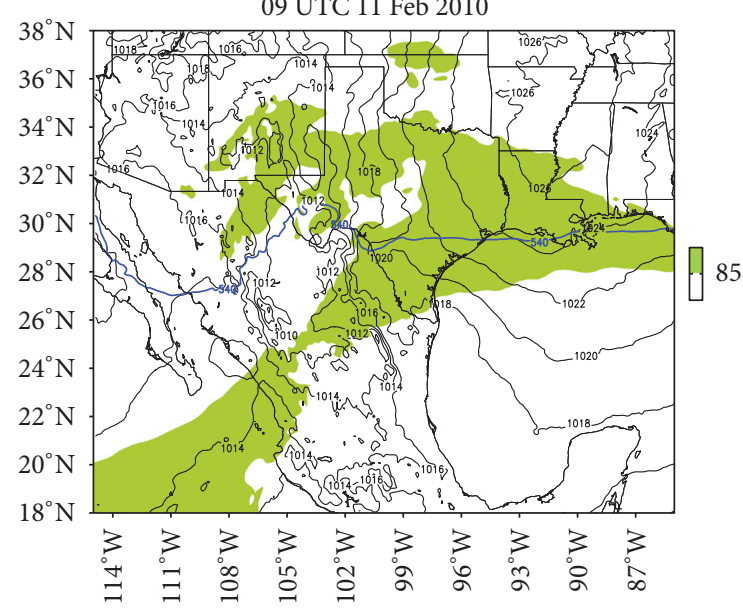

(d)

FIGURE 11: Simulated $(12 \mathrm{~km}$ ) mean sea level pressure (in hPa) $600 \mathrm{hPa}$ relative humidity and 540 dam contour of the 1000-500 hPa thickness on (a) 0000, (b) 0300, (c) 0600, and (d) 0900 UTC 11 February 2010.

$0^{\circ} \mathrm{C}(273.15 \mathrm{~K})$ temperature contour remain steady along the lower Mississippi River Valley. As the LLJ around the trough weakens over Baja California and northern Mexico, the LLJ along the terrain in central Texas increases in speed as the collision of the two LLJs ensue in Figures 12(a)-12(d).

4.2. Evolving Precipitation Bands, Ascent, and Instability over the Collision Zone. High resolution simulation results from the $4 \mathrm{~km}$ domain are employed in this section over the collision zone of multiple fronts and jets to analyze the evolution of banded precipitation, vertical motion, and cross sections of instability. As seen earlier in both radar and $600 \mathrm{hPa} \mathrm{RH}$ images, the atmospheric river moisture sets up banding precipitation across the southern half of Texas while the trough moisture spreads across the northern half of Texas near the panhandle. This is simulated well in the total precipitation accumulations from the initial time across Texas in Figures 13(a)-13(f) to 0600-2100 UTC 11 February.
The northern convective band develops along $\sim 33^{\circ} \mathrm{N}$ and the south central convective band develops below $30^{\circ} \mathrm{N}$. For the next several hours, these mesoscale bands of convection are dominant features with the northern band producing heavy snowfall and the southern band consisting of mixed precipitation. Both bands are aligned along simulated mesoscale frontal zones, one under the PJ and the other under the STJ. By 2100 UTC 11 February, a heavy precipitation bullseye sets up over the FWD, Texas area, approximately near $32^{\circ} \mathrm{N}$ and $98^{\circ} \mathrm{W}$ in Figure 13(f) (similar to what was shown in Figure 2) with the separate convective bands beginning to merge (similar to Figure 3).

Figure 14 illustrates $600 \mathrm{hPa}$ height, wind vectors, and vertical velocity in 3-hour intervals. This indicates areas of significant upward motion (or lift) which helps bring the moisture to condensation and precipitation. Converging winds near the surface $(850 \mathrm{hPa}$ winds of the two LLJs evident in Figure 12) are usually a good indication of upward motion 


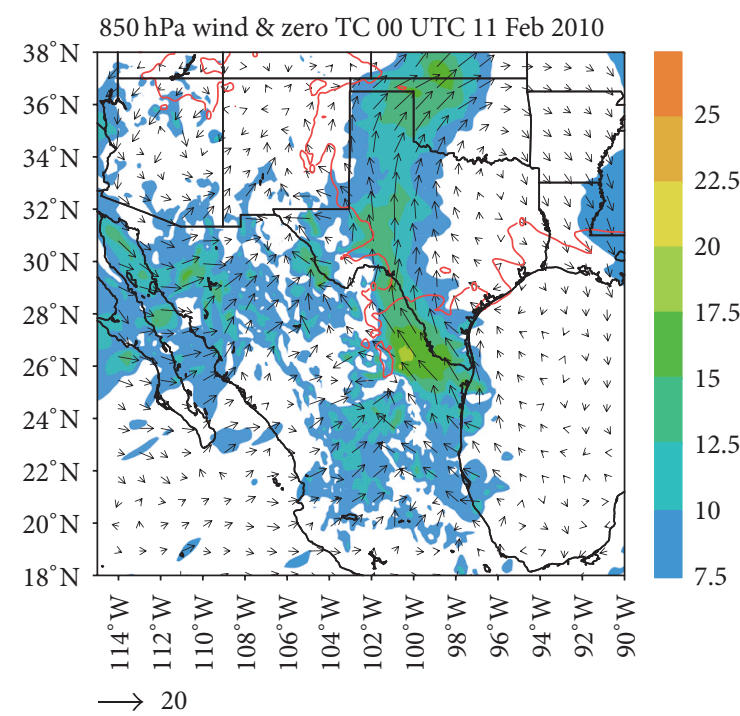

(a)

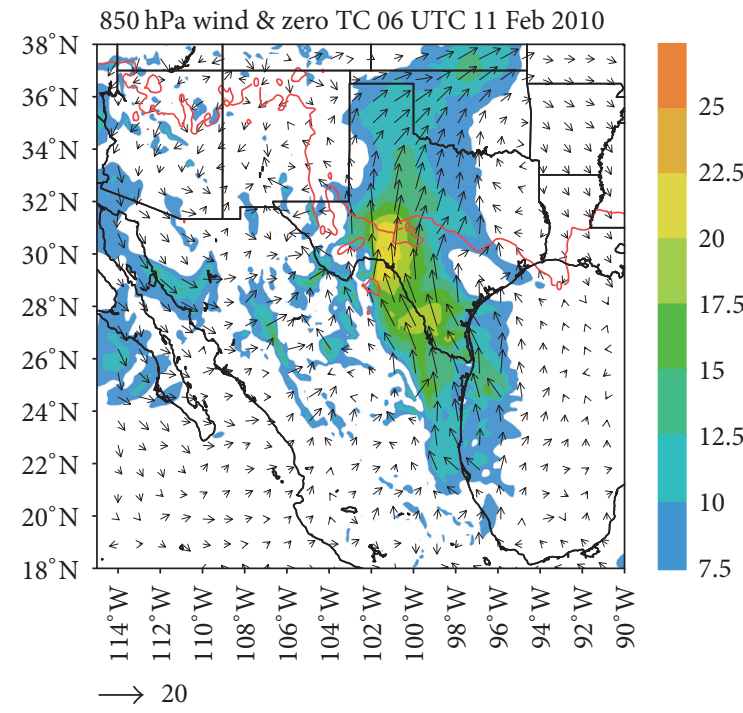

(c)

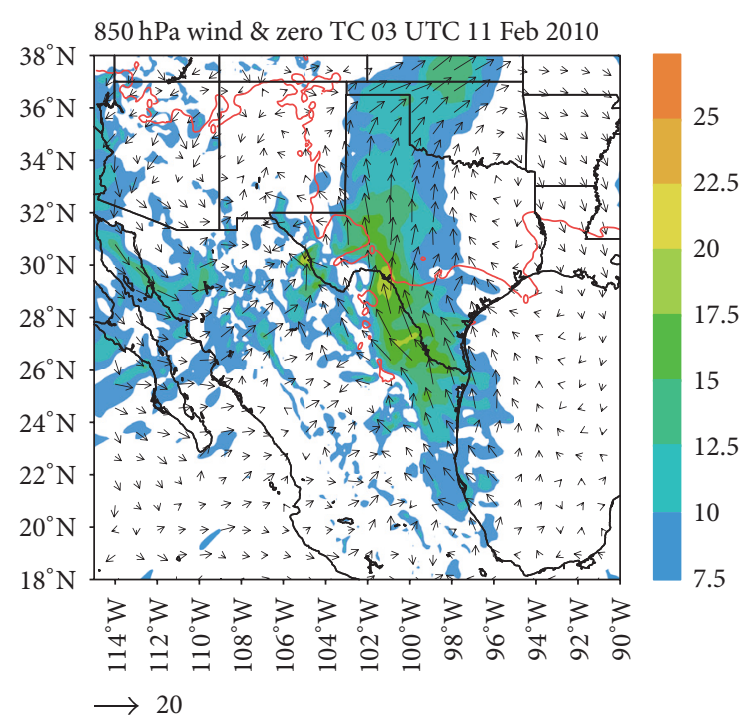

(b)

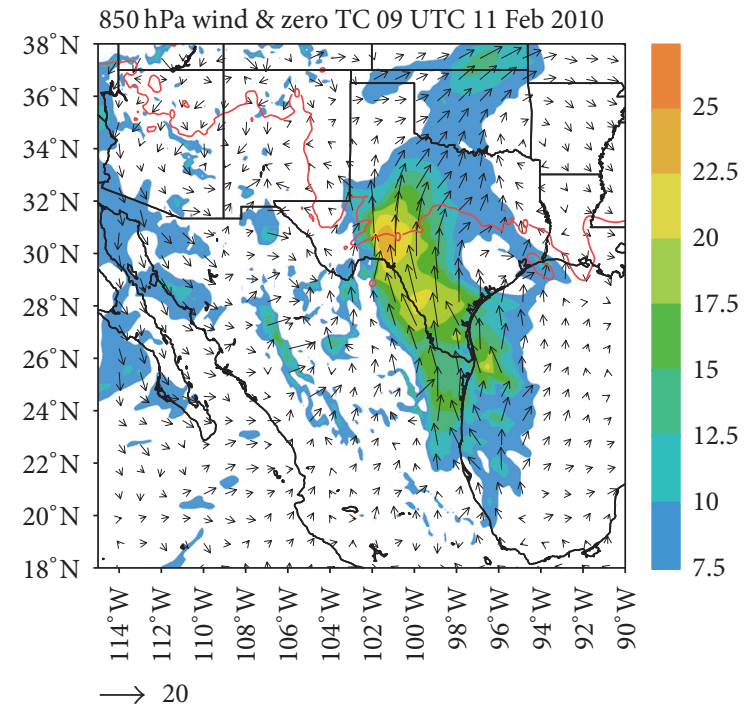

(d)

Figure 12: Simulated $(12 \mathrm{~km}) 850 \mathrm{hPa}$ wind $\left(\mathrm{m} \mathrm{s}^{-1}\right)$ and $0^{\circ} \mathrm{C}(273.15 \mathrm{~K})$ temperature contour on (a) 0000, (b) 0300, (c) 0600, and (d) 0900 UTC 11 February 2010.

in the midlevels and divergence aloft. The orange and red colors in Figure 14 indicate areas of ascent, which build into distinct lines across Texas over time similar to the radar and precipitation images (Figures 3 and 13) showing the evolution of the precipitation bands. Just as the converging winds indicated, there are various areas of upward motion that exist in association with the incoming shortwave trough (or PJ) that propagates into Texas and organizes into distinct lines (Figures 14(a)-14(d)). In Figure 14(d), the upward motion begins to redevelop into multiple southwest to northeastoriented patterns or bands parallel to each other. One band crosses the Texas panhandle and the second one is located underneath, across central Texas as well as a third band across southern Texas into the northern Gulf of Mexico. These bands of vertical motion continue to propagate eastward over the next several hours (Figures 14(d)-14(f)) coming closer together as the system begins to advance into Louisiana and later into the Gulf of Mexico as cyclogenesis commences.

Figure 15 depicts vertical cross sections of saturated equivalent potential temperature $\left(\theta_{e^{*}}\right)$ in the black contours and geostrophic absolute momentum $\left(M_{q}\right)$ in the blue shading below $500 \mathrm{hPa}$ on 0600 and 1800 UTC 11 February (denoted by the black lines in Figures 14(a) and 14(e)). Saturation equivalent potential temperature is defined as $\theta_{e^{*}}=\theta \exp \left(\left(L_{v} r_{s}\right) /\left(C_{p} T\right)\right)$, where $\theta$ is potential temperature, $L_{v}$ is latent heat of vaporization, $r_{s}$ is saturation mixing ratio, $C_{p}$ is specific heat at constant pressure, and $T$ is the mixture temperature (Betts and Dugan 1973 [29]). Figure 15(a) displays conditional instability (CI) between 500 and $800 \mathrm{hPa}$. By definition, CI regions represent an area where $\partial \theta_{e^{*}} / \partial z<0$. 


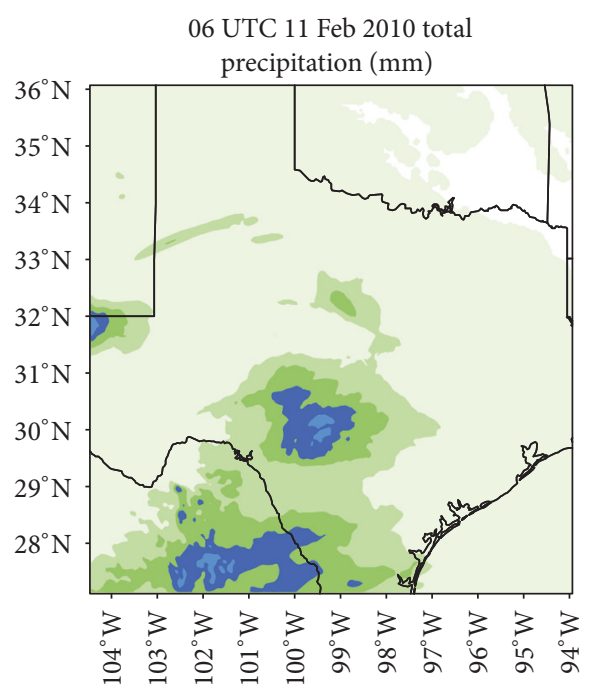

(a)

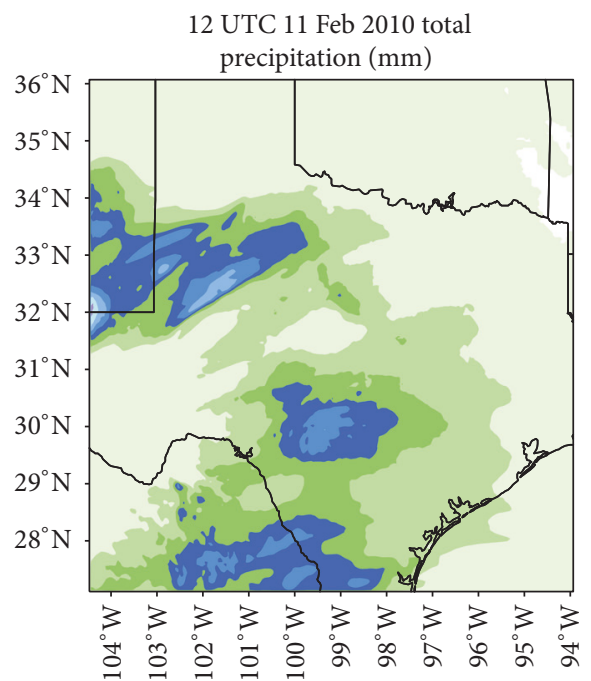

(c)

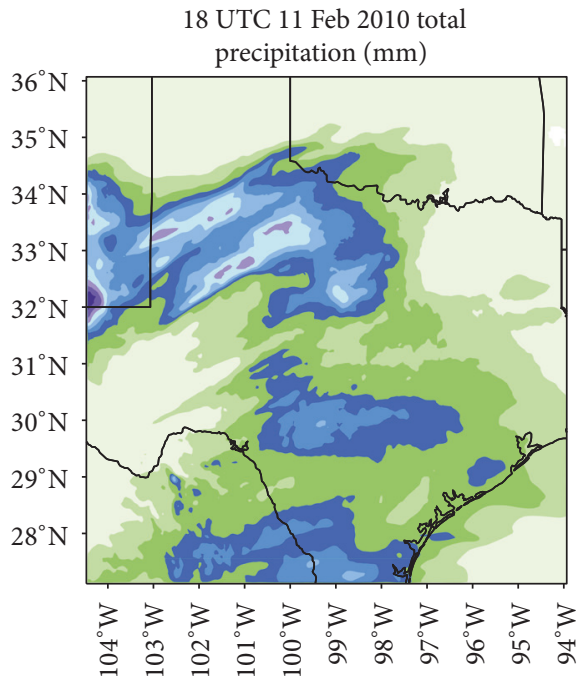

(e)

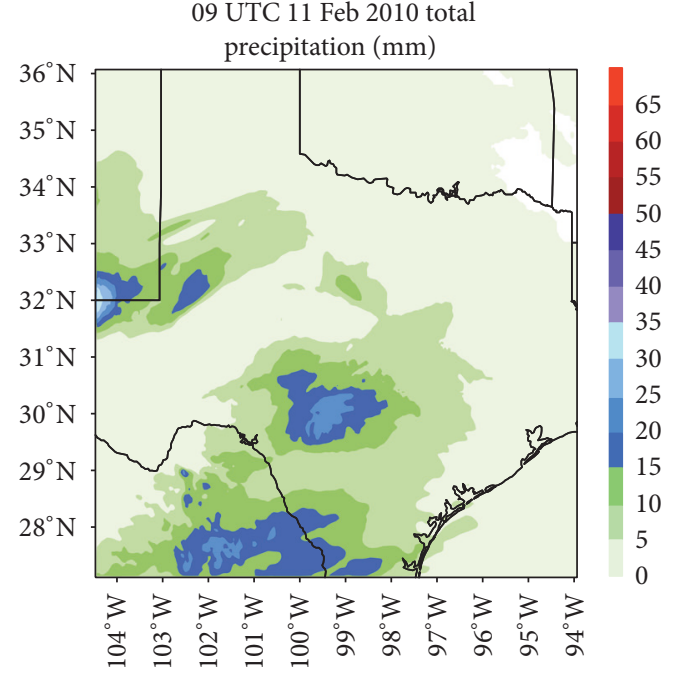

(b)

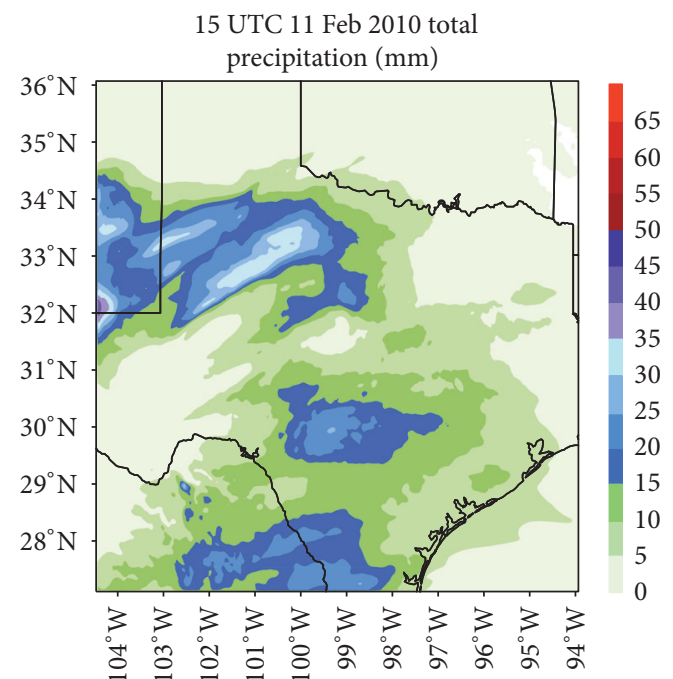

(d)

21 UTC 11 Feb 2010 total precipitation $(\mathrm{mm})$

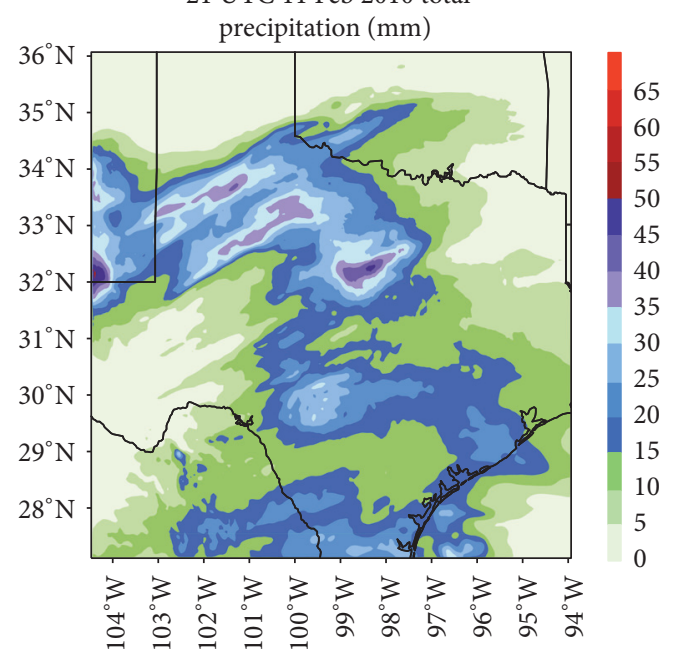

(f)

FIGURE 13: Simulated (4 km) total precipitation (mm) accumulated in 3-hourly intervals on (a) 0600, (b) 0900, (c) 1200, (d) 1500, (e) 1800, and (f) 2100 UTC 11 February 2010. 
$600 \mathrm{hPa}$ hgt., vert. wind, \& vectors 06 UTC 11 Feb 2010

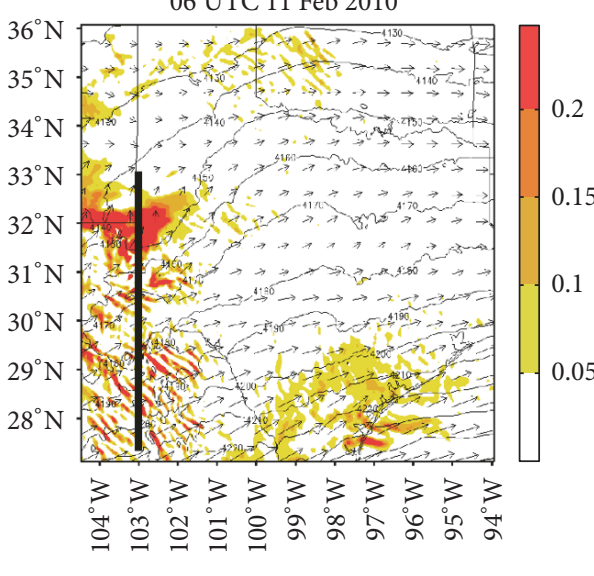

(a)

600 hPa hgt., vert. wind, \& vectors 12 UTC 11 Feb 2010

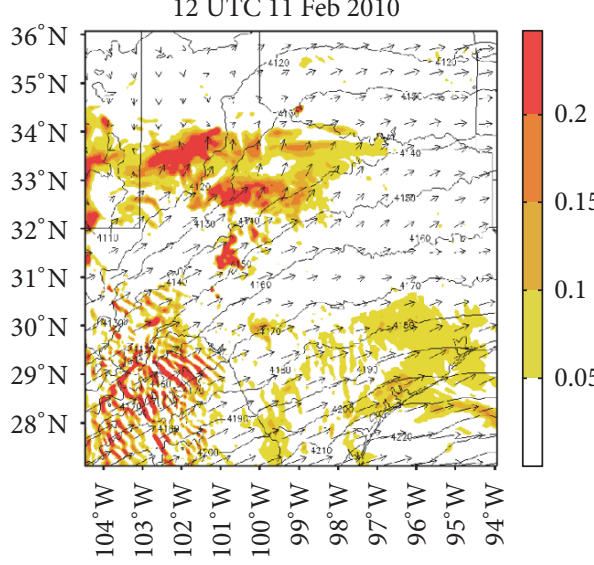

$\longrightarrow 30$

(c)

$600 \mathrm{hPa}$ hgt., vert. wind, \& vectors 18 UTC 11 Feb 2010

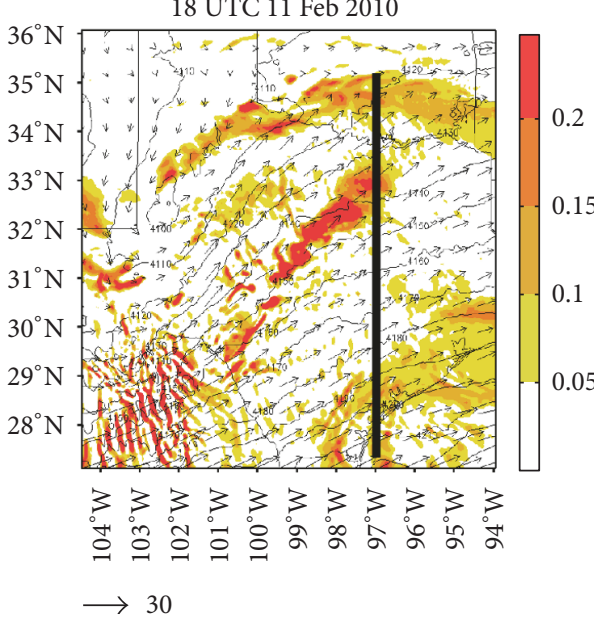

(e)
$600 \mathrm{hPa}$ hgt., vert. wind, \& vectors 09 UTC 11 Feb 2010

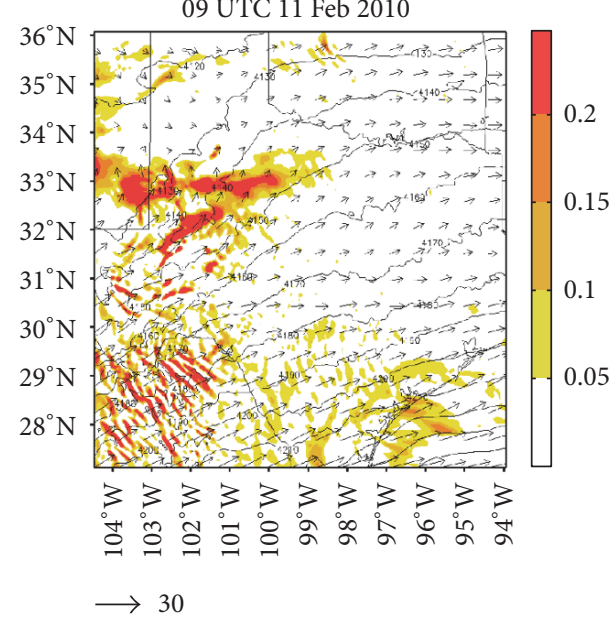

(b)

$600 \mathrm{hPa}$ hgt., vert. wind, \& vectors 15 UTC 11 Feb 2010

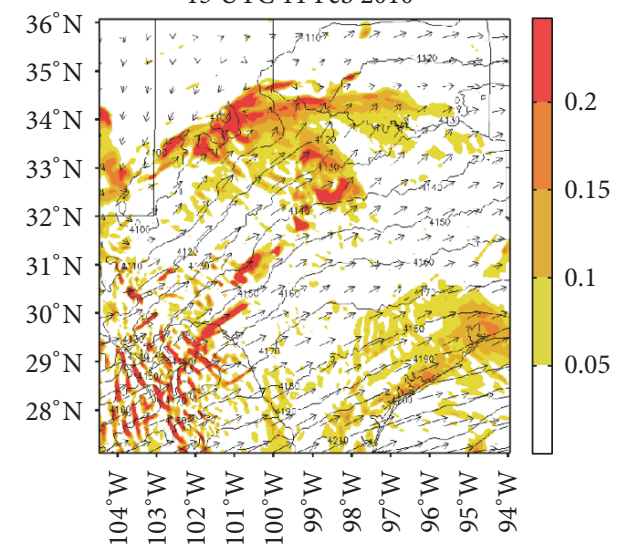

$\longrightarrow 30$

(d)

$600 \mathrm{hPa}$ hgt., vert. wind, \& vectors 21 UTC 11 Feb 2010

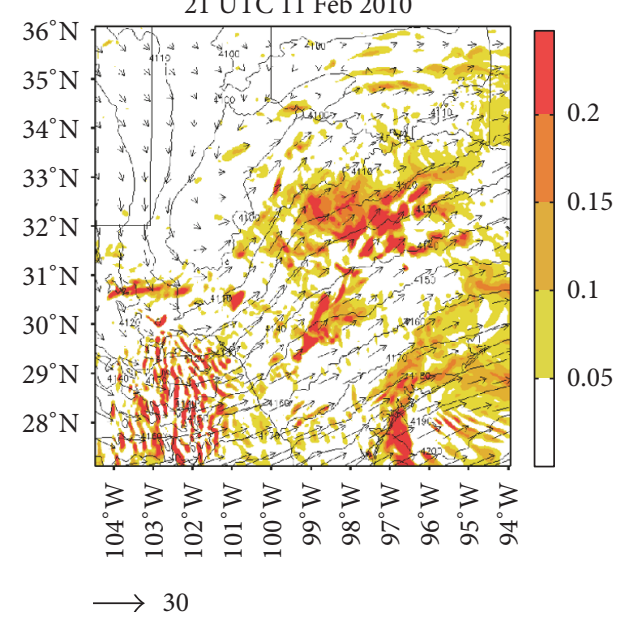

(f)

FigURE 14: Simulated (4 km) $600 \mathrm{hPa}$ wind vectors, height in gpm, and upward vertical wind speed in $\mathrm{m} \mathrm{s}^{-1}$ (shaded) on (a) 0600, (b) 0900, (c) 1200, (d) 1500, (e) 1800, and (f) 2100 UTC 11 February 2010. Black lines denote cross sections taken in Figure 15. 


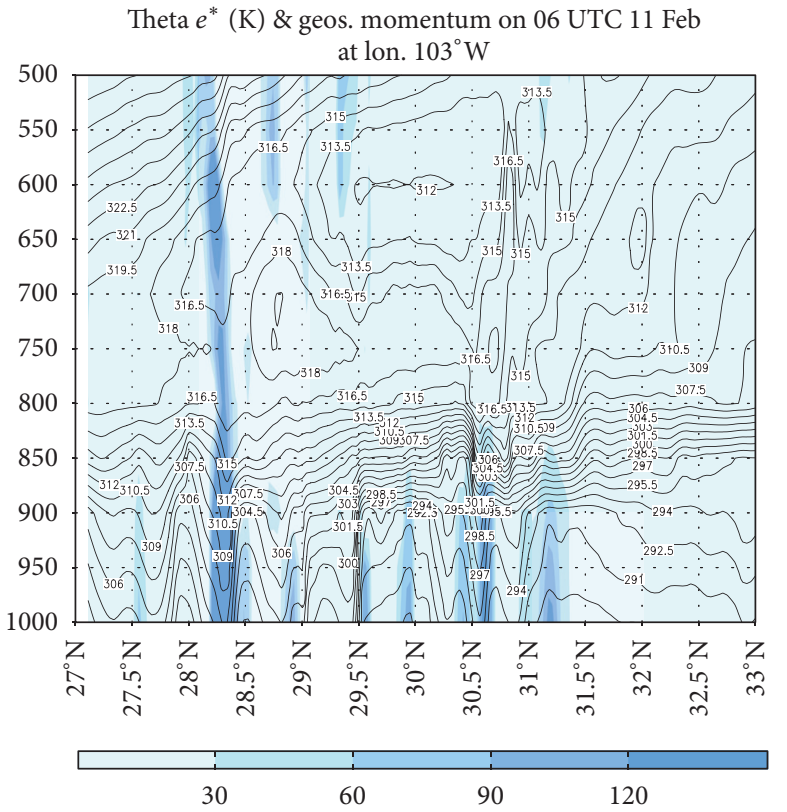

(a)

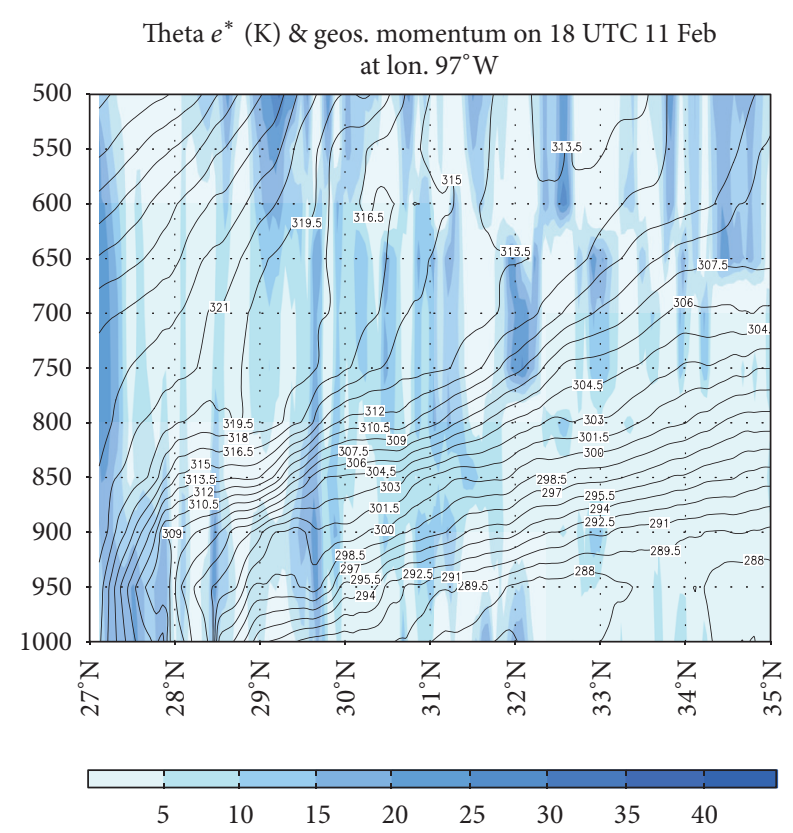

(b)

FIGURE 15: Simulated $(4 \mathrm{~km})$ cross sections displaying theta- $e^{*}(\mathrm{~K})$ and absolute geostrophic momentum $\left(\mathrm{m} \mathrm{s}^{-1}\right)$ at $(\mathrm{a}) 103^{\circ} \mathrm{W}$ on $0600 \mathrm{UTC}$ 11 February and (b) $97^{\circ} \mathrm{W}$ on 1800 UTC 11 February 2010.

This is seen in the vertical variation of $\theta_{e^{*}}$ contours $(318 \mathrm{~K}$ and $312 \mathrm{~K}$ ) folding beneath themselves between 550 and $800 \mathrm{hPa}$. A mixture of both conditional symmetric instability (CSI) and neutral symmetric instability (NS) is located underneath the CI regions below $850 \mathrm{hPa}$ between $28.25^{\circ} \mathrm{N}$ and $31.25^{\circ} \mathrm{N}$. CSI occurs when $\theta_{e^{*}}$ contours have a steeper slope than geostrophic momentum (Schultz and Schumacher 1999 [30]). Geostrophic absolute momentum is defined as $M_{g}=V_{g}+f x$, where $V_{g}$ is the geostrophic wind along the baroclinic zone, $f$ is the Coriolis parameter, and $x$ is the distance across the front. NS occurs when both $\theta_{e^{*}}$ and $M_{g}$ have equal slopes. Over the next 12 hours in Figure 15(b), the mesoscale instabilities weaken substantially as the system propagates further away from the terrain. CSI, NS, and CI are coexisting predominately south of $32^{\circ} \mathrm{N}$. Although they are relatively weak, the presence of CI, CSI, and NS is signals of upright and slantwise convection leading to the heavy precipitation bands across the southeast US. It can be very hard for the model to simulate these mesoscale instabilities; therefore other diagnoses tools will be utilized later.

4.3. Sensitivity Experiments. The purpose of the sensitivity experiments is to examine the effects of the Sierra Madre Mountains in Mexico and neighboring plateau, microphysics heating, and surface heat/moisture flux on the overall intensity of the snowstorm and the development of its features. To test the orographic effects of the Sierra Madre Mountains and neighboring elevated plateau in Texas, the terrain was reduced to 225 meters (LMTN). For the effects of microphysics heating (NMPH) and surface heat and moisture flux (NSFF) on the developing snowstorm, these WRF options were turned off. Figures 16(a)-16(f) display the $300 \mathrm{hPa}$ wind and geopotential height evolution for each sensitivity experiment from 0000-0300 UTC 11 February. As described earlier in the $300 \mathrm{hPa}$ wind images in Figure 10(a), the polar and subtropical jet streaks start off in a side by side position across Baja California into Mexico with the subtropical jet streak being noticeably weaker. Three hours later on 0300 UTC 11 February, the "race effect" results in an energy boost for the STJ streak to race ahead of the PJ streak across central Texas. Then on 0600 and 0900 UTC 11 February, the STJ streak acts as bridge to merge the PJ streak over northern Mexico with an even stronger jet streak associated with a strong Nor'easter. The evolution of the upper level jet streaks in the LMTN experiment (Figures 16(a)-16(b)), compared to the control experiment (CTRL) in Figures 10(a) and 10 (c), is very similar. One difference is that the PJ and STJ streaks in the CTRL experiment are stronger than in the LMTN case (Figures 16(a)-16(b)). The upper level jet of the western half of the domain in the NMPH case (Figures 16(c)-16(d)) does not share any resemblance of the PJ or STJ positioning that sets up across Mexico into Texas for the CTRL or LMTN experiments. This emphasizes an extremely important relationship between latent heating and synoptic scale upper level jet circulations/streak formations. The jet streak evolution for the NSFF case in Figures 16(e)-16(f) resembles that of both the CTRL and LMTN experiments.

Figures 17(a)-17(f) capture MSLP, $600 \mathrm{hPa}$ RH, and 540 dam contour of the $1000-500 \mathrm{hPa}$ thickness on 0000 and 0600 UTC 11 February for the sensitivity experiments. As described earlier in Figure 11(d), the moisture collision between the incoming shortwave trough and the atmospheric river occurs on 0900 UTC 11 February near FWD, Texas, for the CTRL simulation. However, all three sensitivity 


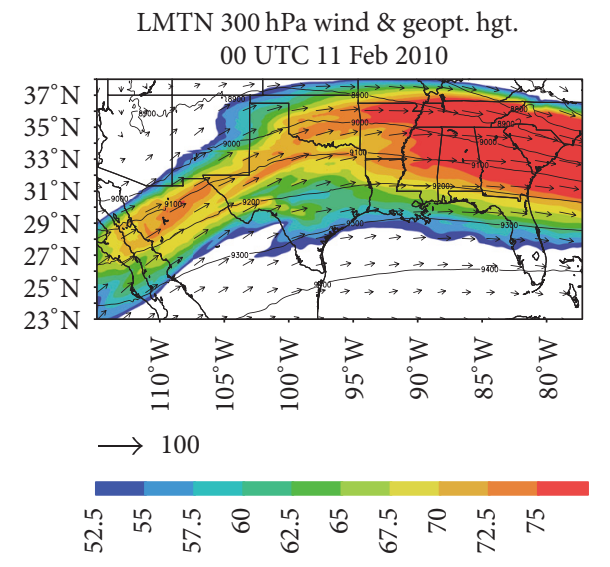

(a)

NMPH 300 hPa wind \& geopt. hgt.

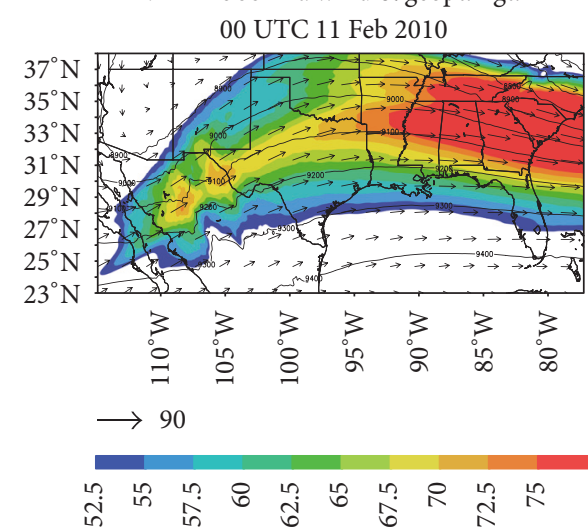

(c)

NSFF $300 \mathrm{hPa}$ wind \& geopt. hgt. 00 UTC 11 Feb 2010

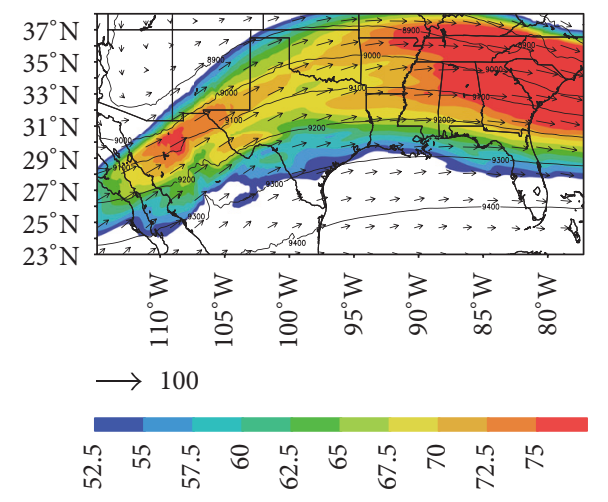

(e)
LMTN $300 \mathrm{hPa}$ wind \& geopt. hgt. 03 UTC 11 Feb 2010

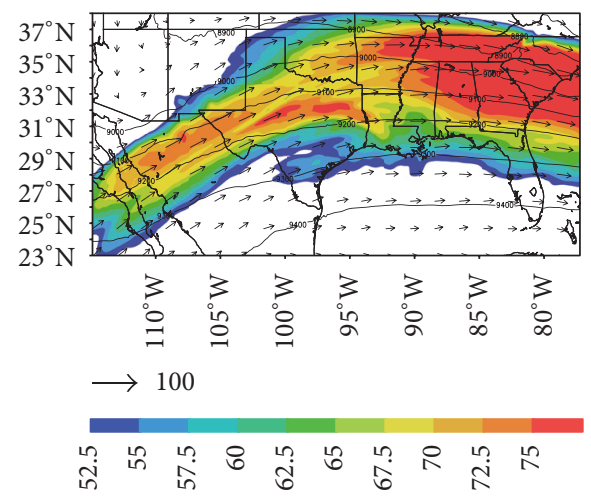

(b)

NMPH $300 \mathrm{hPa}$ wind \& geopt. hgt.

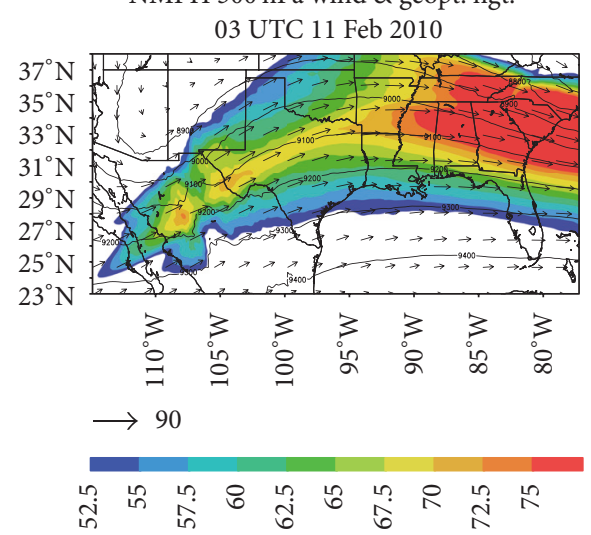

(d)

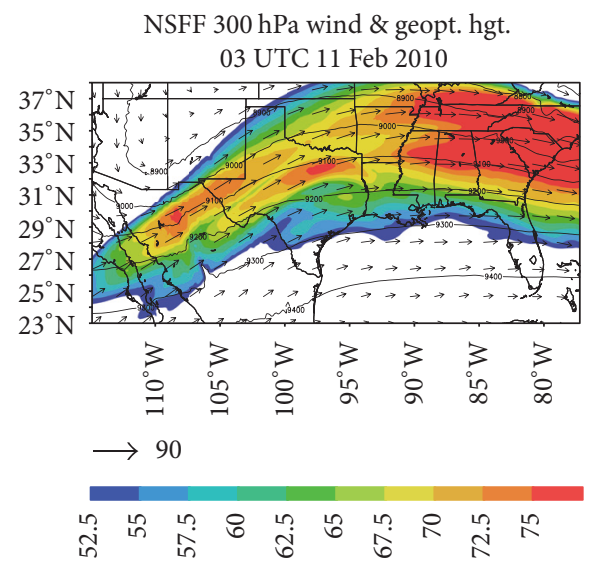

(f)

FIGURE 16: Simulated $(12 \mathrm{~km}) 300 \mathrm{hPa}$ wind $\left(\mathrm{m} \mathrm{s}^{-1}\right)$ and geopotential height in gpm on 0000 and 0300 UTC 11 February 2010 for (a-b) terrain reduction experiment, (c-d) no microphysics heating experiment, and (e-f) no surface flux experiment.

experiments experience this collision prior to 0900 UTC 11 February. The collision zone for the CTRL and LMTN simulation differs in both location and timing. The LMTN case collision occurs over western Texas on 0300 UTC 11 February between Figures 17(a) and 17(b). For the NMPH case in Figures 17(c)-17(d), the collision takes place earlier than any other experiment on 1800 UTC 10 February (not shown). The positioning of the moisture in Figure 17(e) and the later collision zone in Figure 17(f) for the NSFF case occurs most similarly to the CTRL experiment, where the collision occurs only three hours prior to the CTRL run on 0600 UTC 11 February and slightly west of FWD, Texas.

Figure 18 compares $850 \mathrm{hPa}$ wind and $0^{\circ} \mathrm{C}(273.15 \mathrm{~K})$ temperature contour of the sensitivity experiments on 0000 
LMTN 00 UTC 11 Feb 2010

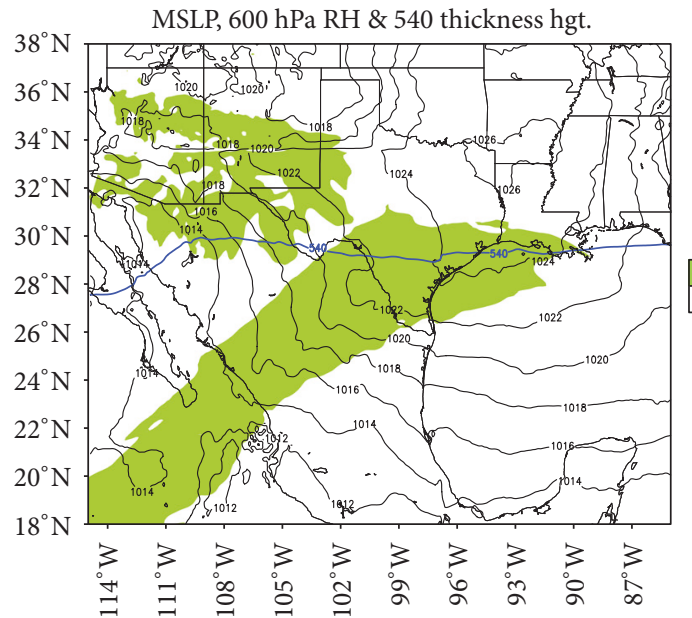

(a)

NMPH 00 UTC 11 Feb 2010

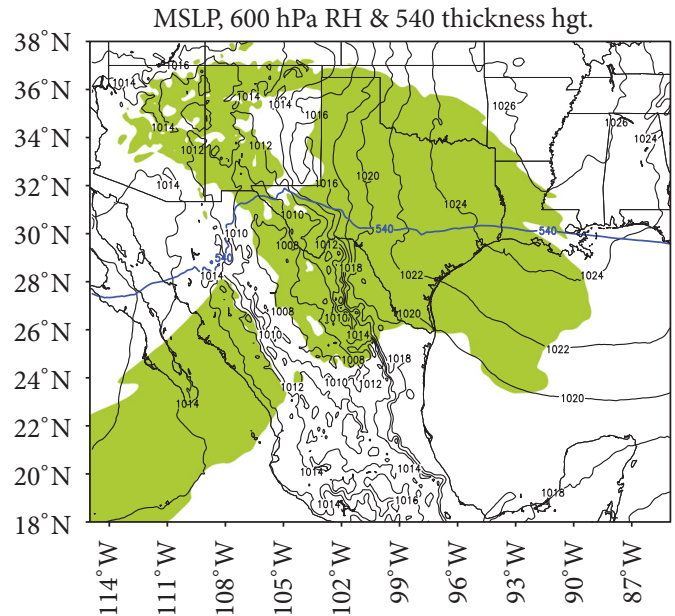

(c)

NSFF 00 UTC 11 Feb 2010

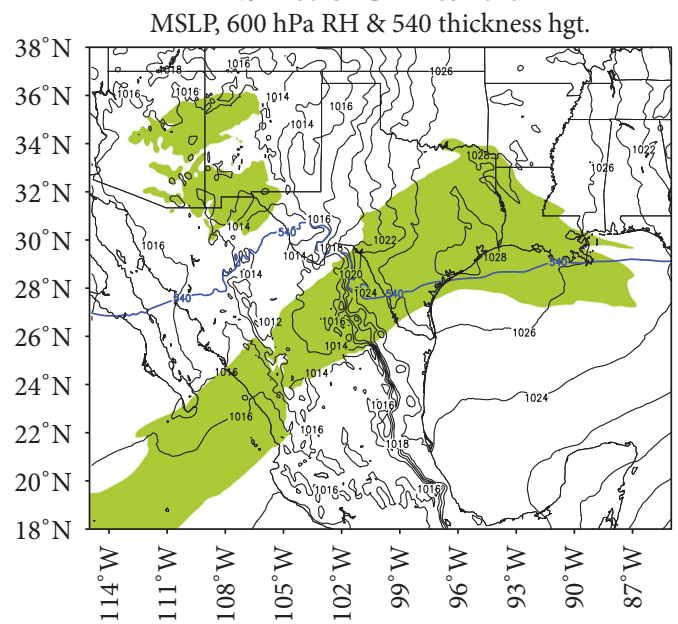

(e)
LMTN 06 UTC 11 Feb 2010

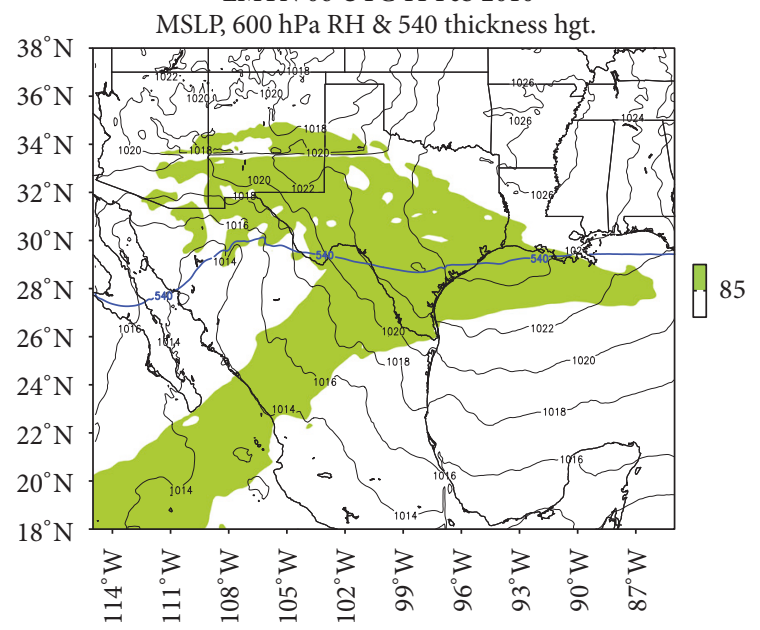

(b)

NMPH 06 UTC 11 Feb 2010

MSLP, 600 hPa RH \& 540 thickness hgt.

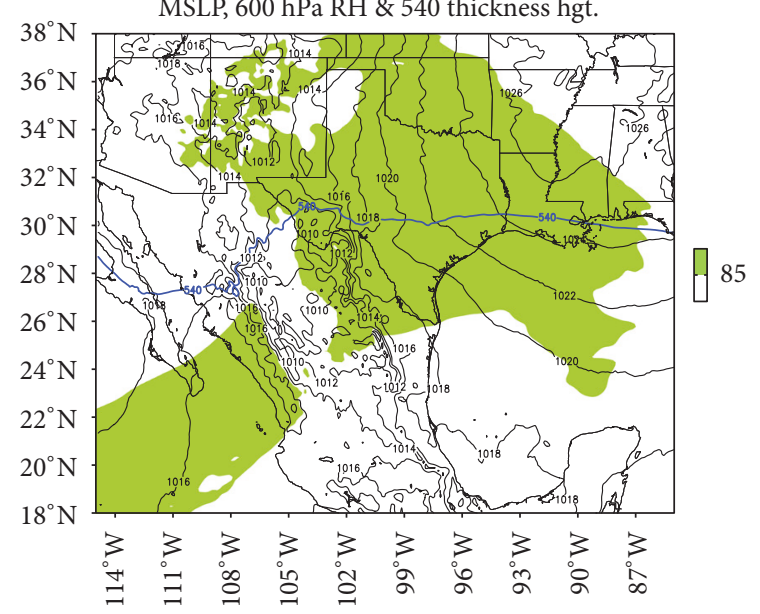

(d)

NSFF 06 UTC 11 Feb 2010

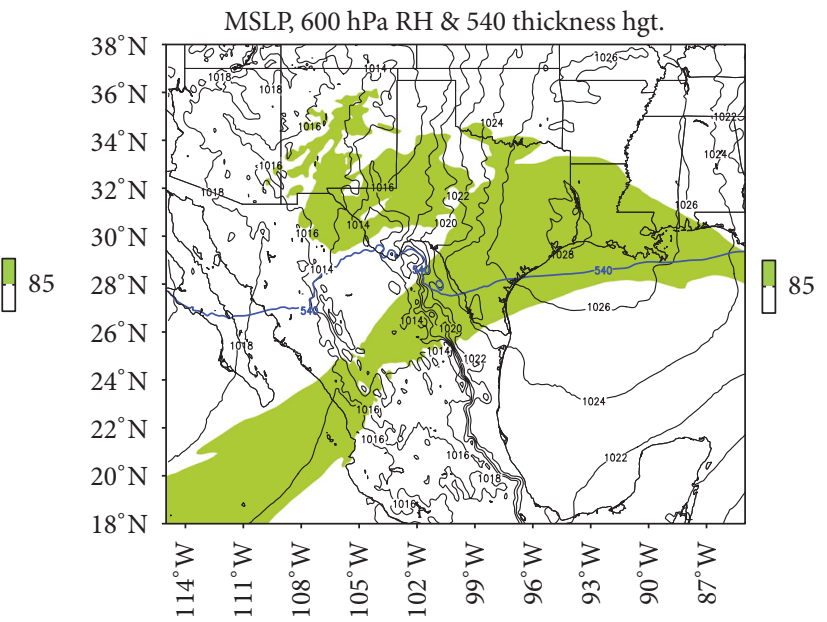

(f)

FIGURE 17: Simulated $(12 \mathrm{~km}$ ) mean sea level pressure (in hPa), $600 \mathrm{hPa}$ relative humidity, and 540 dam contour of the $1000-500 \mathrm{hPa}$ thickness (in blue) on 0000 and 0600 UTC 11 February 2010 for (a-b) terrain reduction experiment, (c-d) no microphysics heating experiment, and (e-f) no surface flux experiment. 


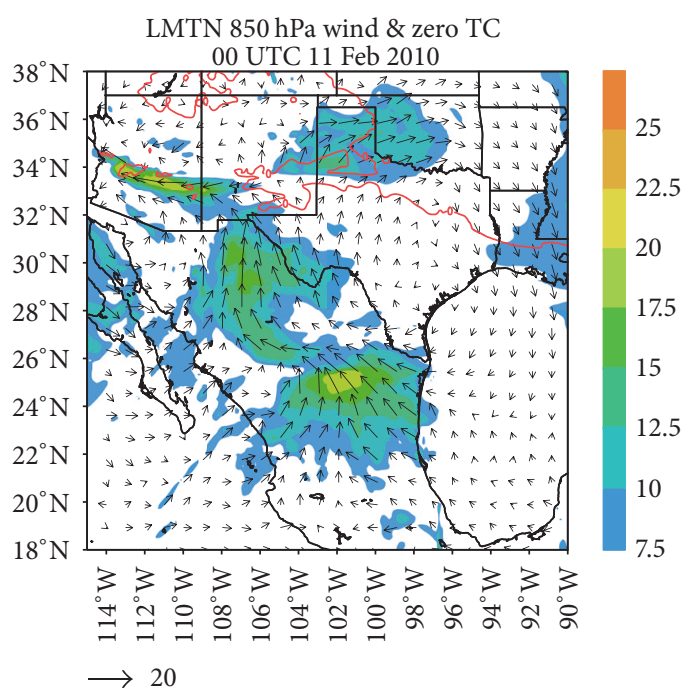

(a)

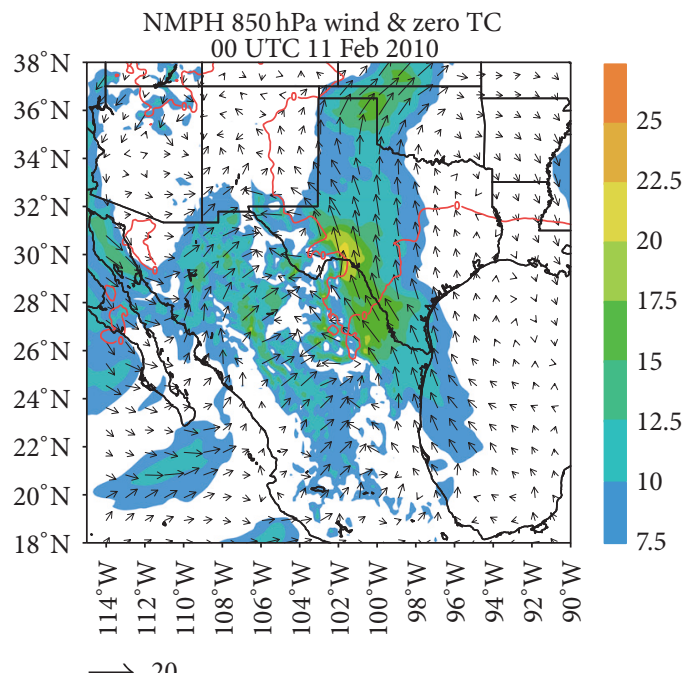

(c)

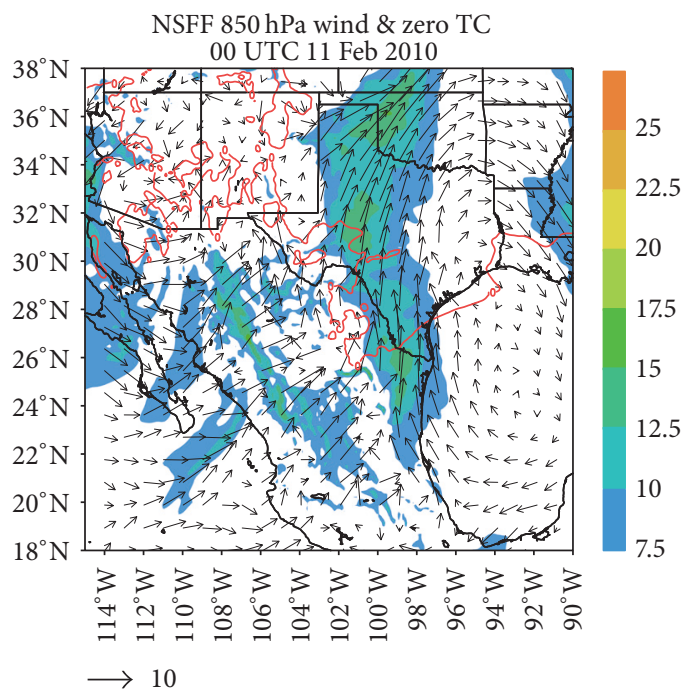

(e)

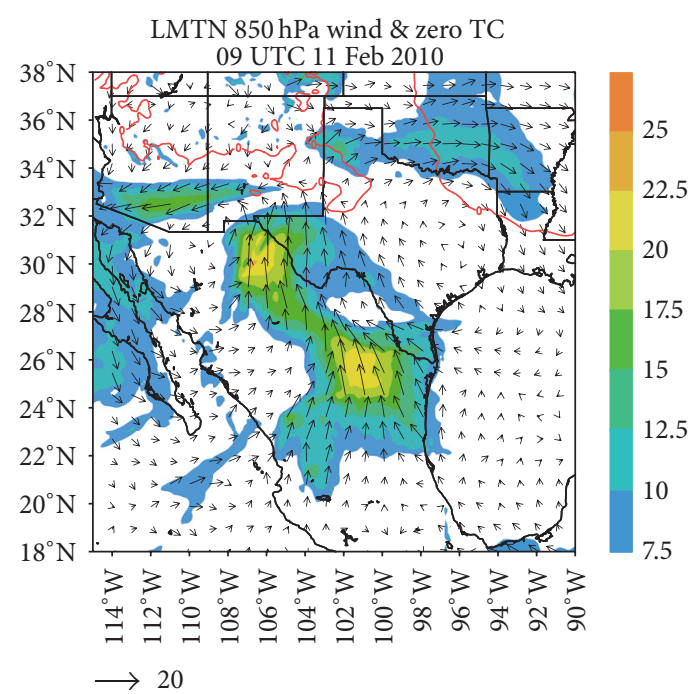

(b)

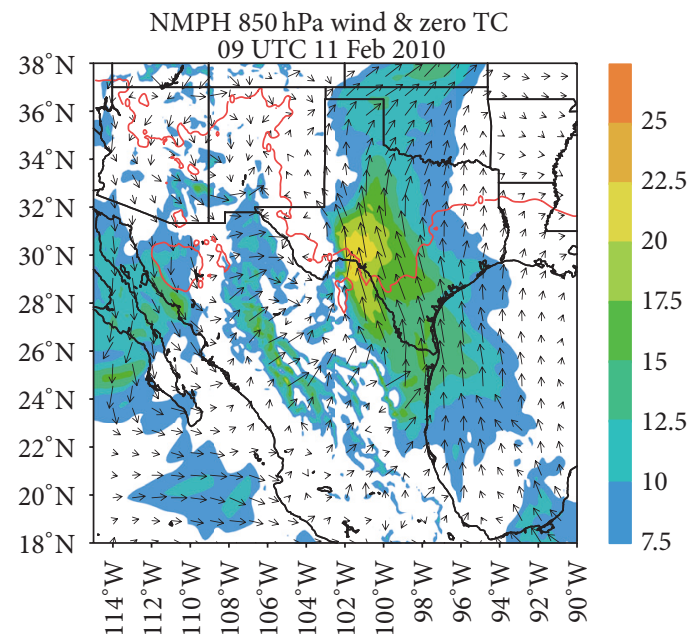

$\longrightarrow 20$

(d)

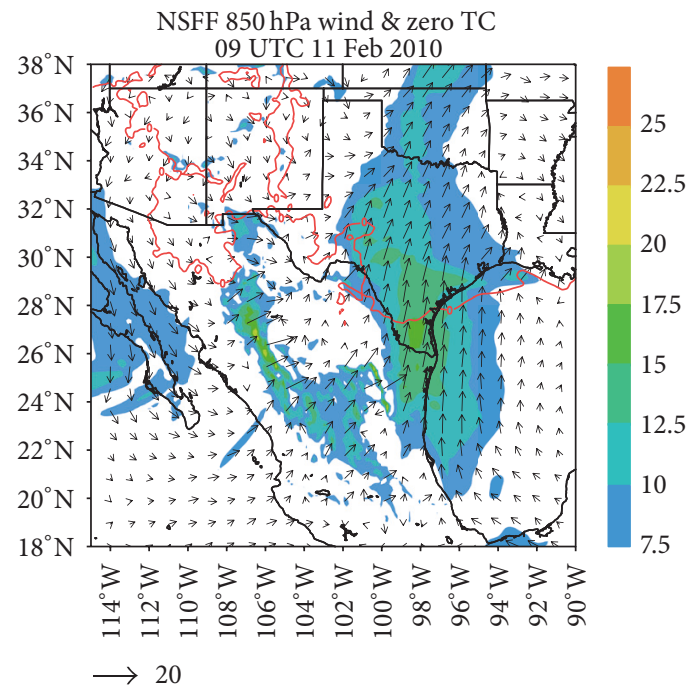

(f)

FIGURE 18: Simulated $(12 \mathrm{~km}) 850 \mathrm{hPa}$ wind $\left(\mathrm{m} \mathrm{s}^{-1}\right)$ and $0^{\circ} \mathrm{C}(273.15 \mathrm{~K})$ temperature contour on 0000 and 0900 UTC 11 February 2010 for (a-b) terrain reduction experiment, (c-d) no microphysics heating experiment, and (e-f) no surface flux experiment. 
and 0900 UTC 11 February. The CTRL experiment in Figures 12(a) and 12(d) shows a larger, colder pool of air associated across Texas (above the $0^{\circ} \mathrm{C}$ temperature contour) than the LMTN experiment in Figures 18(a)-18(b). There is a clear distinction between the dual LLJs (one along the incoming trough and the other around the anticyclone across the southeast) collision zone over Mexico in the LMTN case versus the CTRL case which is harder to see in Figure 12. The NMPH simulation in Figures 18(c)-18(d) has a similar temperature pattern as the CTRL run and the NSFF experiment has the coldest temperatures out of all the sensitivity experiments in Figures 18(e)-18(f). Both the NMPH and NSFF cases display dual LLJs similar to the CTRL case; however, the NSFF simulation has the weakest LLJs of all the sensitivity experiments.

Figures 19-20 capture $850 \mathrm{hPa}$ streamlines, potential vorticity, and $700 \mathrm{hPa}$ frontogenesis on 1800 UTC 11 February and 0600 UTC 12 February for each experiment. It can be very difficult for the model to correctly simulate areas of instability (specifically CI, NS, and CSI), but plotting the areas of convergence, low-to-negative potential vorticity, and positive frontogenesis is also a good way to help identify/diagnose regions of instability. During the genesis of extreme moist convection over west Texas $\sim 0600$ UTC 11 February (see Figure 15(a), where vertically erect isentropes can be seen near $28.5^{\circ} \mathrm{N}, 29.5^{\circ} \mathrm{N}$, and $31^{\circ} \mathrm{N}$ ), the aforementioned precipitation bands formed close to the adjustments leading to the dual LLJ convergence zone. This convergence zone consists of arctic air dammed against the Sierra Madre Oriental, northward against the elevated plateau across Texas, and the polar boundary associated with the incoming shortwave trough. In the CTRL case (Figure 19(a)), the convergence zone between the trough over western Texas and the anticyclone over Arkansas has set up over central and southeastern Texas in an area of low-to-negative potential vorticity and positive frontogenesis (Figure 19(b)). The locations of the trough, anticyclone, area of convergence, and positive frontogenesis in the LMTN experiment are positioned to the south and east of the CTRL run in Figures 19(c)-19(d). Areas of convergence near negative potential vorticity and positive frontogenesis are located along the Louisiana coastline in both the NMPH and NSFF cases in Figures 19(e)-19(h), but these areas are not as strong and widespread as the CTRL and LMTN cases. Figures 20(a)-20(d) denote the southeastward movement of confluence, negative potential vorticity, and positive frontogenesis as cyclogenesis is occurring over the northern Gulf of Mexico for the CTRL and over the southern Texas and northern Mexico in the LMTN case. Areas of confluence, negative potential vorticity, and positive frontogenesis in Figures 20(e)-20(h) were not as intense for the NMPH and NSFF cases as the CTRL and LMTN experiments.

The simulated total precipitation from initial time to 0600 and 1800 UTC 12 February 2010 is denoted in Figures 21(a)-21(h) for the sensitivity experiments. The CTRL case correctly simulates the bullseye over the FWD, Texas, as well as the southeastward spread of precipitation across the lower Mississippi River Valley similar to what is seen in Figure 2. None of the sensitivity experiments were able to correctly simulate the bullseye over FWD, Texas in Figures 21(c)-21(h). The heavier localized precipitation regions in Figure 21 correlate with the areas of confluence, low-to-negative potential vorticity, and positive frontogenesis seen in Figures 1920 . Figures $22(a)-22(d)$ compare the simulated snow and ice accumulations (or frozen precipitation accumulations at the surface) from initial time to 0000 UTC 14 February for the sensitivity runs. Notice that there is almost a lack of snowfall across Texas in the LMTN and NMPH cases (Figures 22(b)22(c)) compared to the CTRL (Figure 22(a)). This strongly emphasizes the importance of the synergistic interactions between terrain blocking and latent heat effects on this record breaking snowfall event. Although it is relatively weaker, the NSFF experiment in Figure 22(d) has the most resemblance to the CTRL case.

\section{Summary}

Prior studies indicating common synoptic scale features of southern US snowstorms were examined in the case study analysis of the record breaking Deep South Snowstorm February 11-12, 2010, by employing multilevel, multiscaled observations, reanalysis data, and numerical simulations. The first part of this research paper shows the collision course of several upper/lower level jets that resulted in synergistic interactions that lead to snowfall accumulation amounts $>6$ inches $(15.24 \mathrm{~cm})$ over the deep south US prior to cyclogenesis. Multilevel winds from the arctic, polar, and subtropical jet airstreams collide across Texas. A merged polar/subtropical LLJ collides with an arctic LLJ associated with a deep anticyclone that extends well into the Gulf of Mexico bringing cold arctic air to the southern states. As the cold anticyclonic wind flow reaches the terrain barrier of the Sierra Madre Mountains in Mexico and the local elevated plateau in Texas, blocking (or CAD) occurs on the lee side of the terrain creating strong low-level flow northward along the terrain barrier. The merged westerly LLJ collides with the cold easterly LLJ as it makes a sharp turn to the north due to the terrain, which creates double LLJ flow into central Texas. As the collided system of polar, subtropical, and arctic air streams progress eastward, cyclogenesis takes place in the Gulf of Mexico.

As the "race effect" between the upper level PJ and STJ streaks takes place, the overlapping of multiple jet streak entrances/exits occur across the southeast. The LLJs act as a lifting mechanism resulting in two preferred zones of moist convection. The poleward zone produces convective instability (CI) where the low-level arctic front undercuts the polar front. This organizes the initial convection that produces snowfall near FWD that subsequently spreads downstream. The equatorward zone of moist convection (with coexisting CI, NS, and CSI) triggers much more moisture south of $30^{\circ} \mathrm{N}$ over areas of convergence, low-to-negative potential vorticity, and positive frontogenesis ahead of the anticyclonic flow. While this is occurring, offshore warm waters and cooling aloft accompanying the incoming shortwave trough produce cyclogenesis in Gulf of Mexico.

Three sensitivity experiments were conducted to test their effects on the developing snowstorm. (1) Mountainous terrain height was reduced to 225 meters (LMTN) to test the orographic effects of the Sierra Madre Mountains in Mexico and Texas plateau. (2) The microphysics heating is turned off 
CTRL 18 UTC 11 Feb

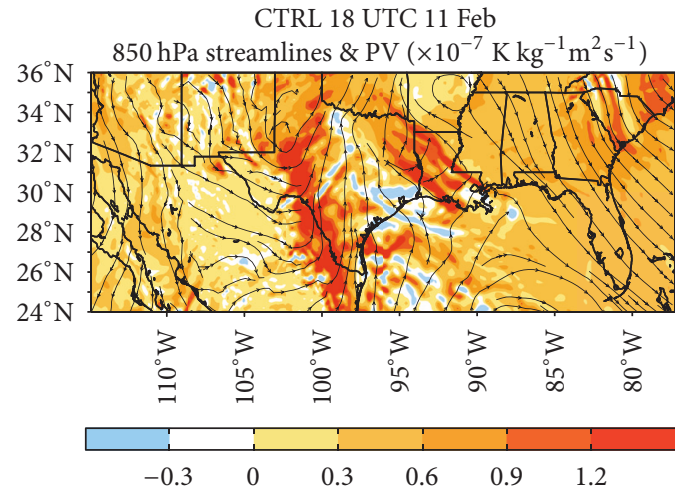

(a)

LMTN 18 UTC $11 \mathrm{Feb}$

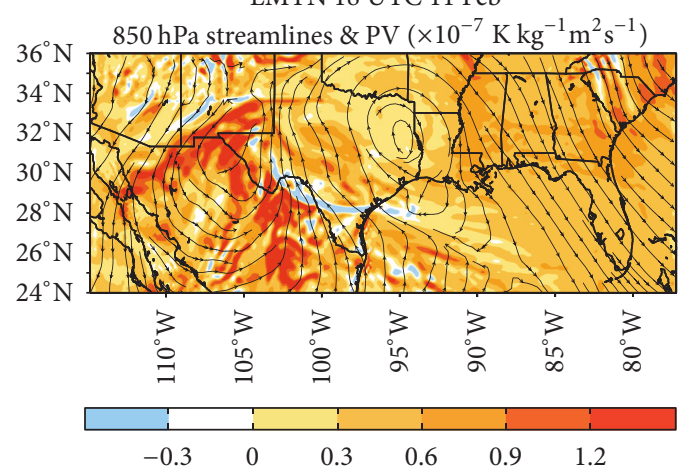

(c)

NMPH 18 UTC 11 Feb

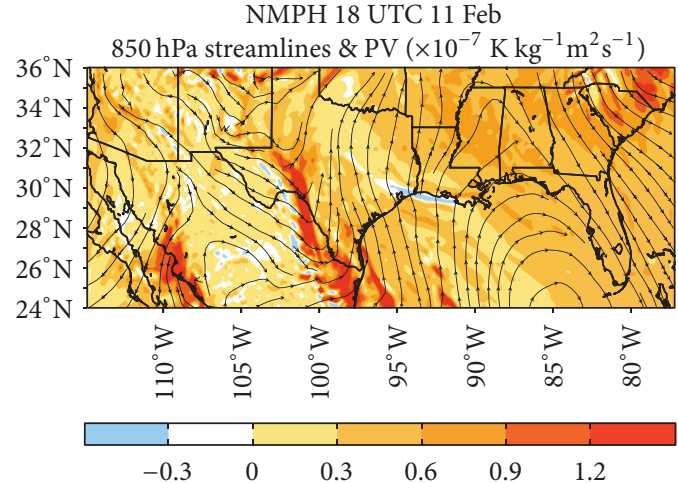

(e)

NSFF 18 UTC 11 Feb $850 \mathrm{hPa}$ streamlines \& PV $\left(\times 10^{-7} \mathrm{~K} \mathrm{~kg}^{-1} \mathrm{~m}^{2} \mathrm{~s}^{-1}\right)$

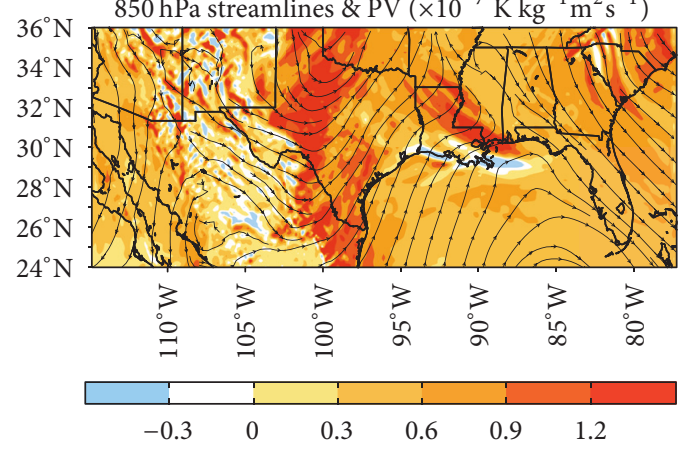

(g)

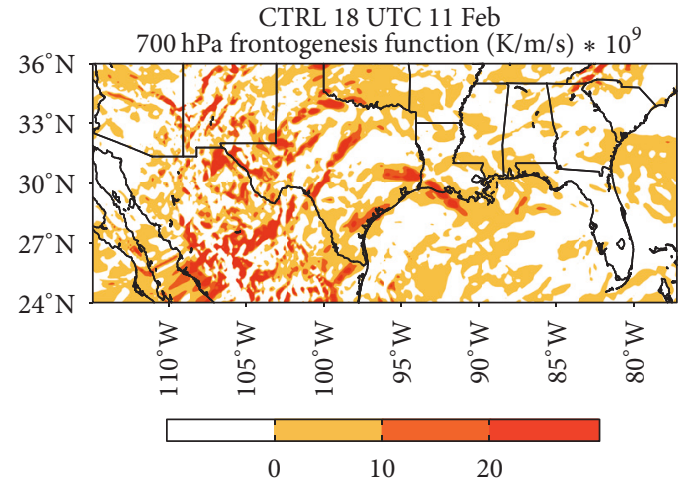

(b)

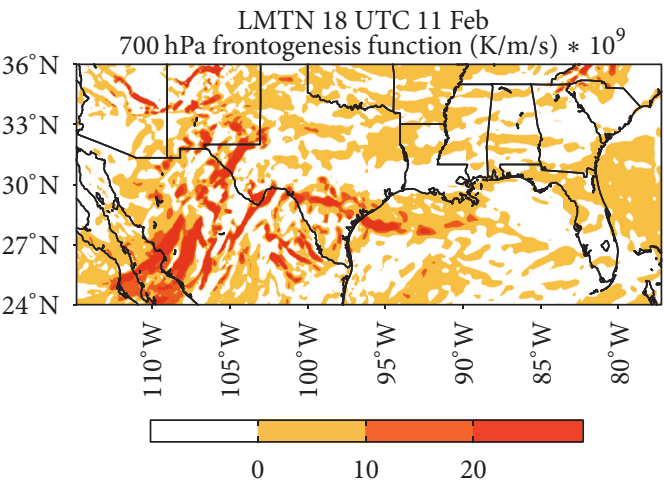

(d)

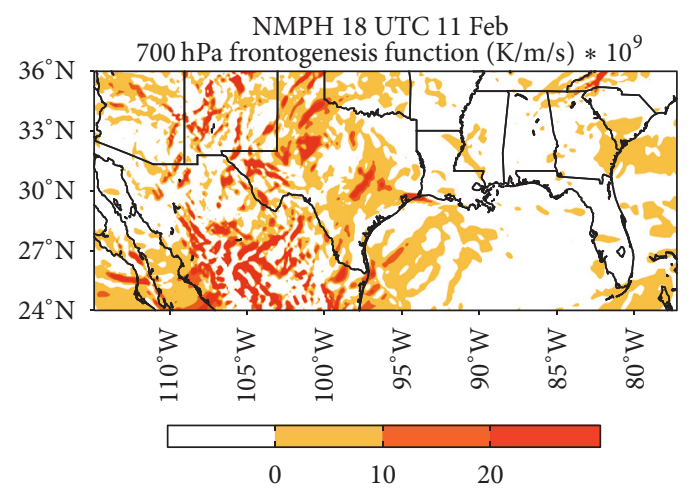

(f)

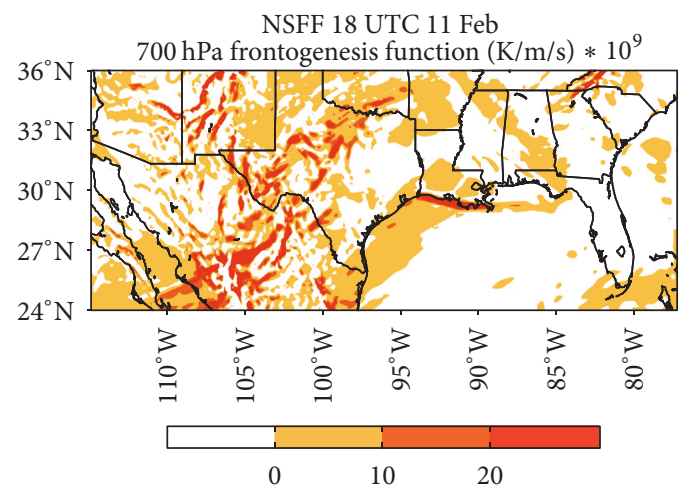

(h)

Figure 19: Simulated $(12 \mathrm{~km}) 850 \mathrm{hPa}$ streamlines, potential vorticity, and $700 \mathrm{hPa}$ frontogenesis on 1800 UTC 11 February 2010 for (a-b) control experiment, (c-d) terrain reduction experiment, (e-f) no microphysics heating experiment, and (g-h) no surface flux experiment. 


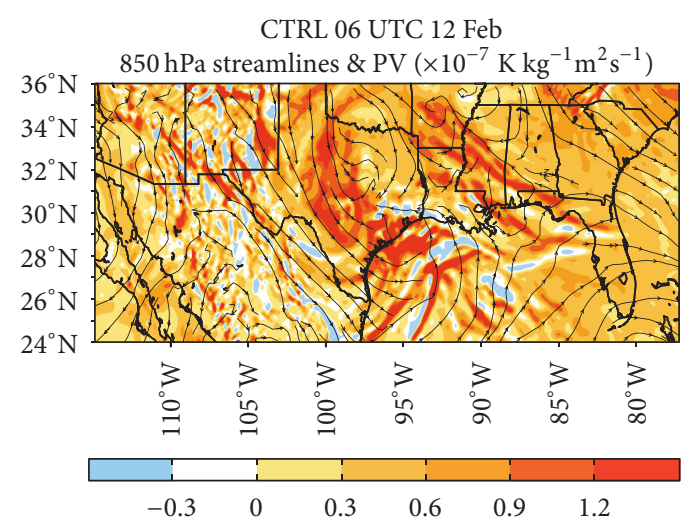

(a)

LMTN 06 UTC 12 Feb

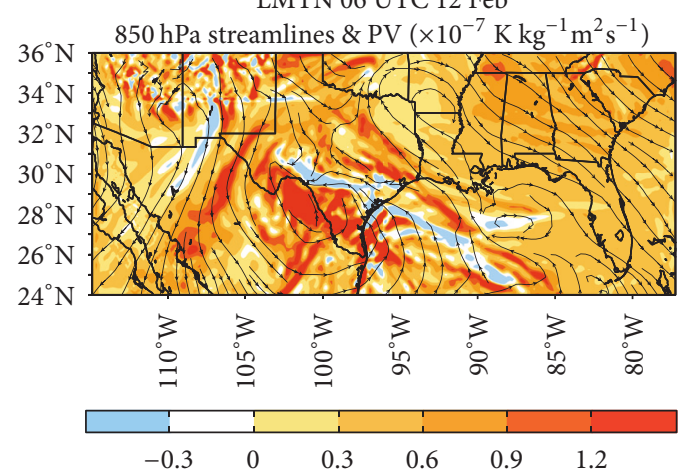

(c)

NMPH 06 UTC 12 Feb

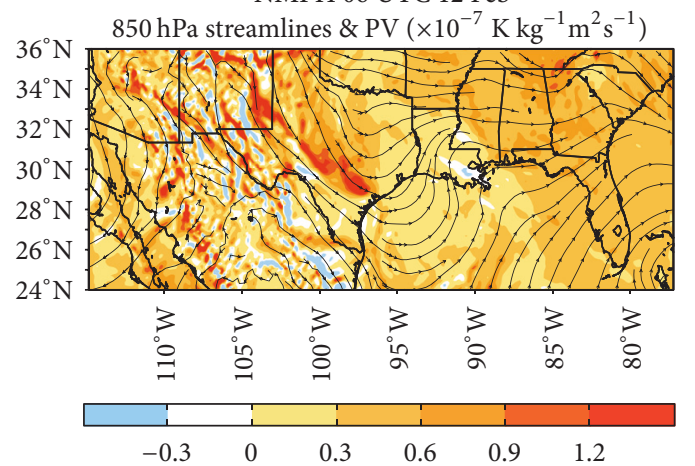

(e)

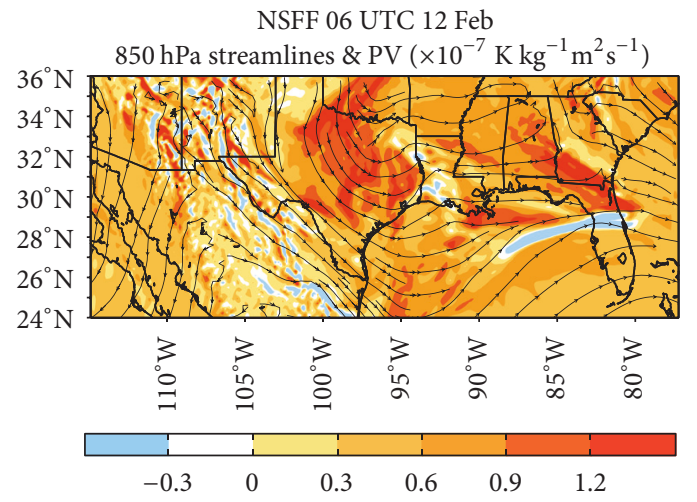

(g)

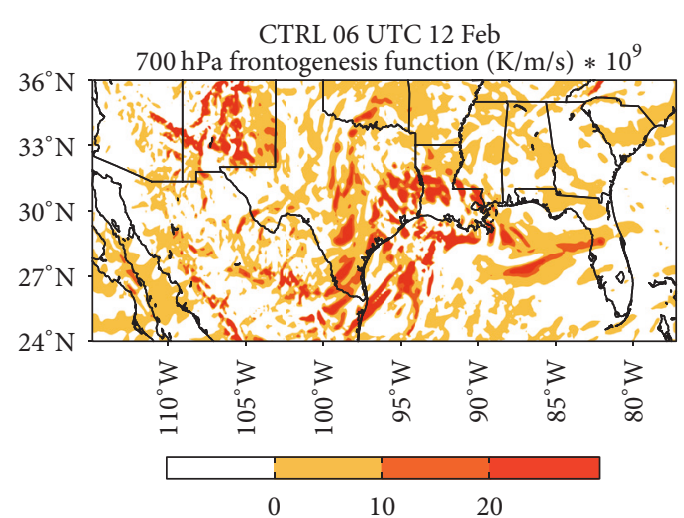

(b)

LMTN 06 UTC 12 Feb

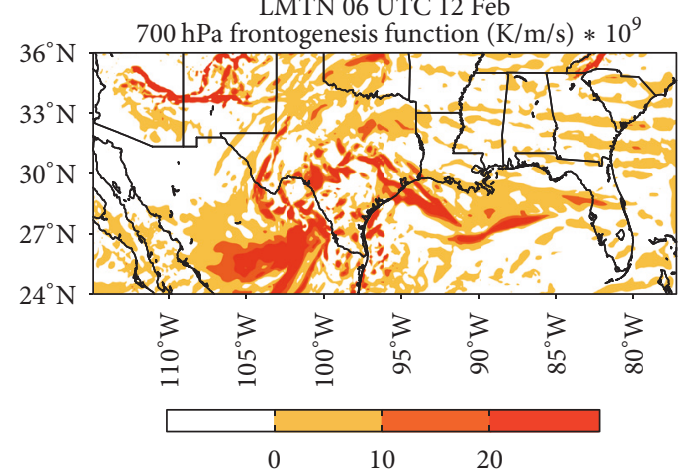

(d)

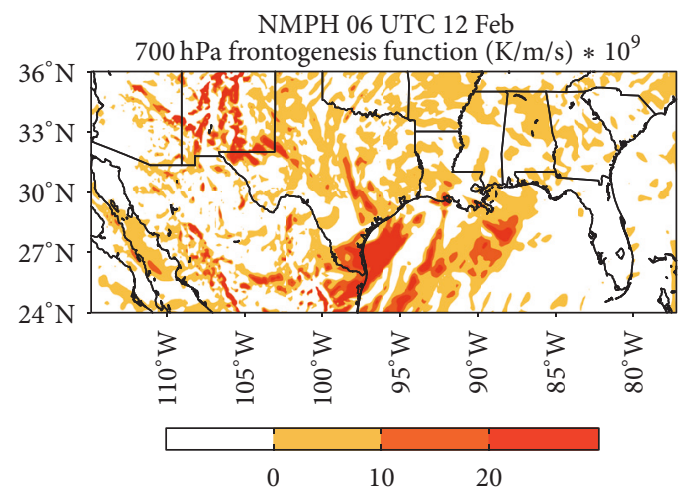

(f)

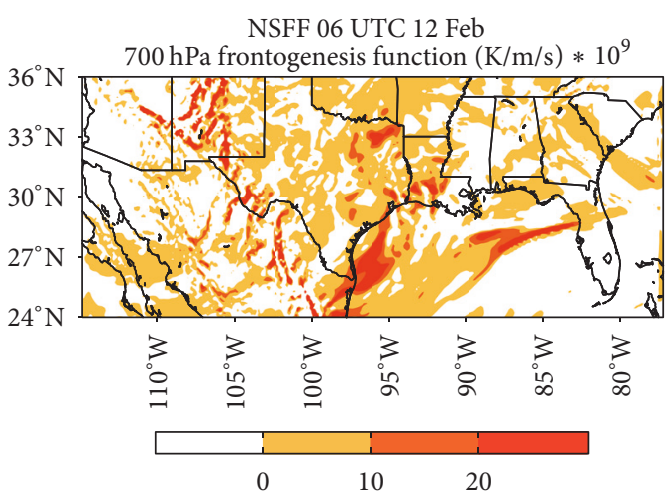

(h)

FIGURE 20: Simulated $(12 \mathrm{~km}) 850 \mathrm{hPa}$ streamlines, potential vorticity, and $700 \mathrm{hPa}$ frontogenesis on 0600 UTC 12 February 2010 for (a-b) control experiment, (c-d) terrain reduction experiment, (e-f) no microphysics heating experiment, and (g-h) no surface flux experiment. 
CTRL 06 UTC 12 Feb 2010 total percipitation $(\mathrm{mm})$
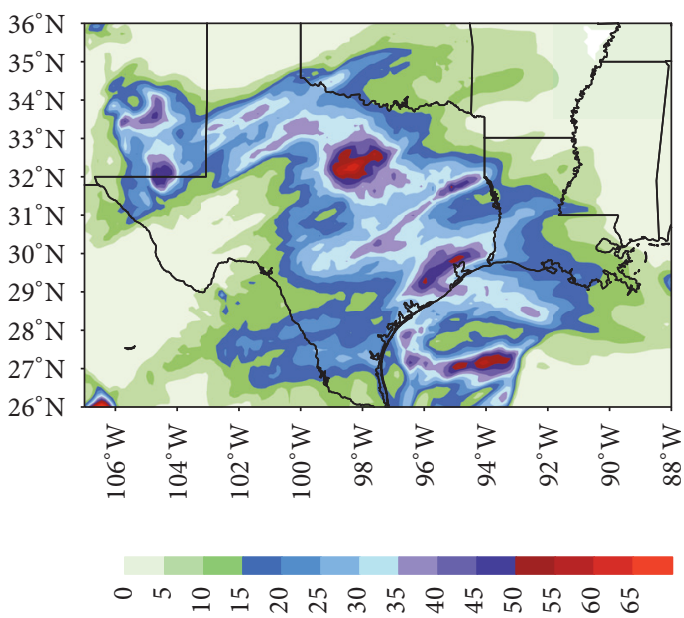

(a)

LMTN 06 UTC 12 Feb 2010 total percipitation $(\mathrm{mm})$
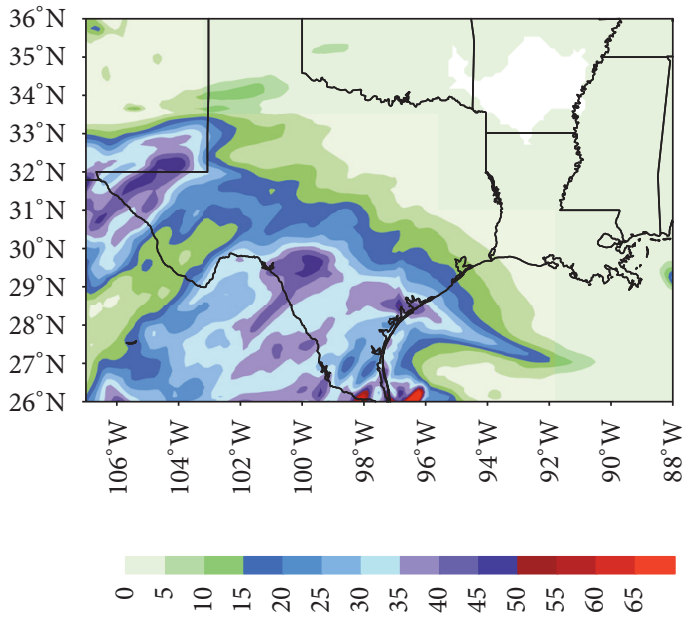

(c)

NMPH 06 UTC 12 Feb 2010 total percipitation $(\mathrm{mm})$

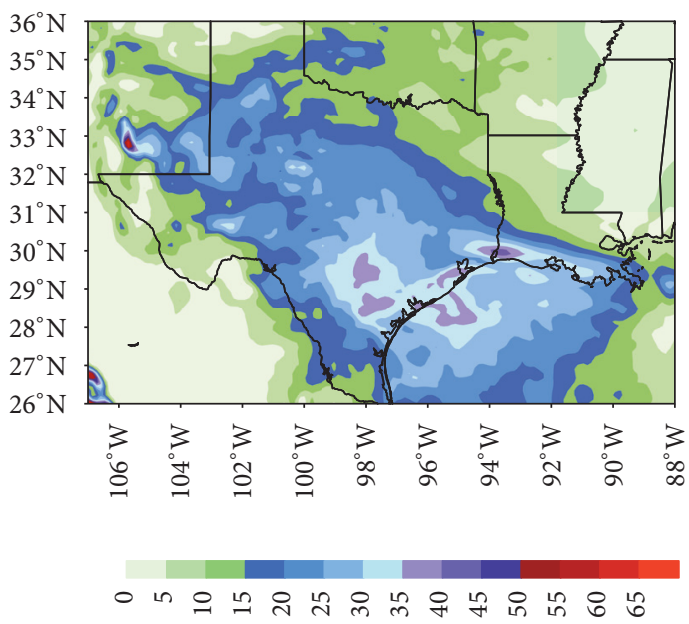

(e)
CTRL 18 UTC 12 Feb 2010 total percipitation $(\mathrm{mm})$

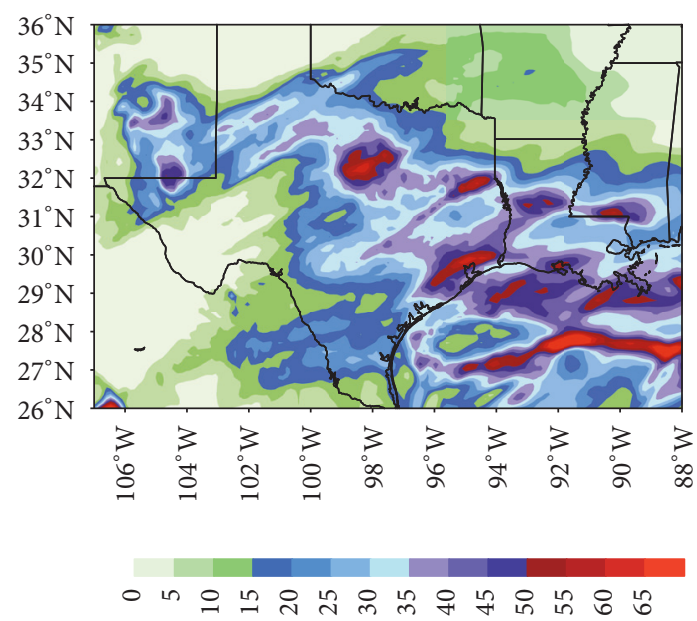

(b)

LMTN 18 UTC 12 Feb 2010 total percipitation $(\mathrm{mm})$
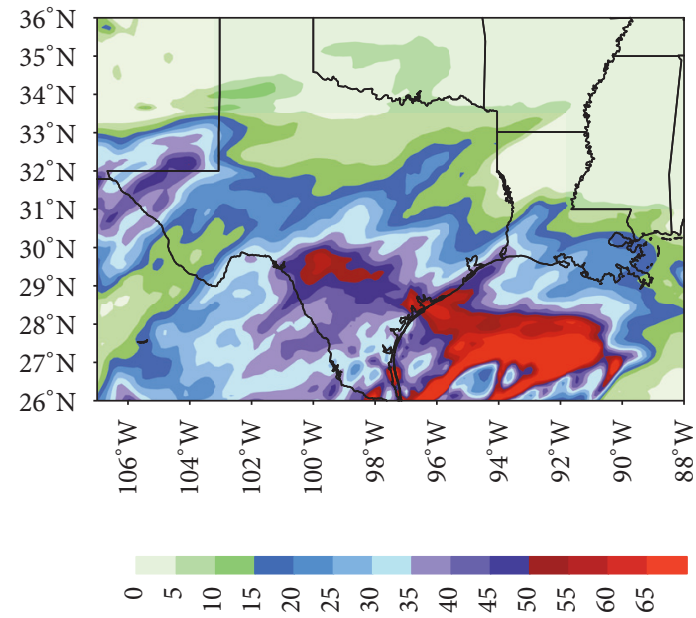

(d)

NMPH 18 UTC 12 Feb 2010 total percipitation $(\mathrm{mm})$

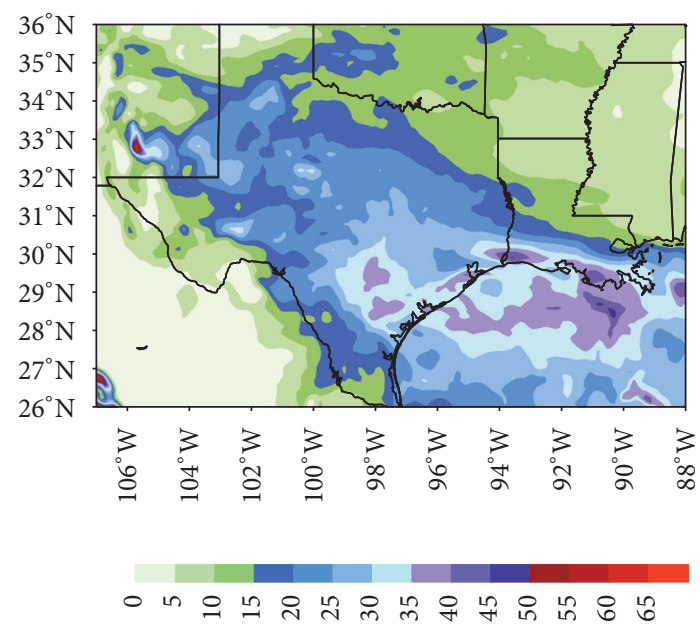

(f)

Figure 21: Continued. 
NSFF 06 UTC 12 Feb 2010 total percipitation $(\mathrm{mm})$

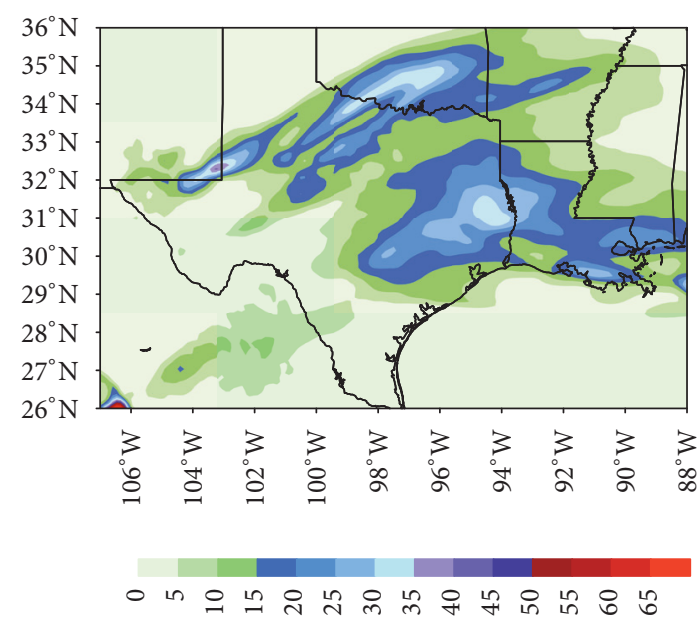

(g)
NSFF 18 UTC 12 Feb 2010 total percipitation $(\mathrm{mm})$

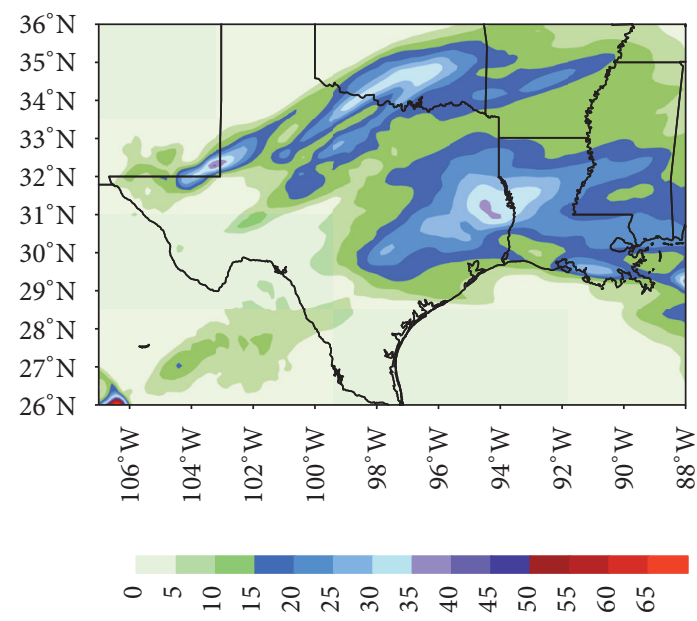

(h)

FIGURE 21: Simulated $(12 \mathrm{~km})$ total precipitation $(\mathrm{mm})$ on 0600 and 1800 UTC 12 February 2010 for (a-b) control experiment, (c-d) terrain reduction experiment, (e-f) no microphysics heating experiment, and (g-h) no surface flux experiment.

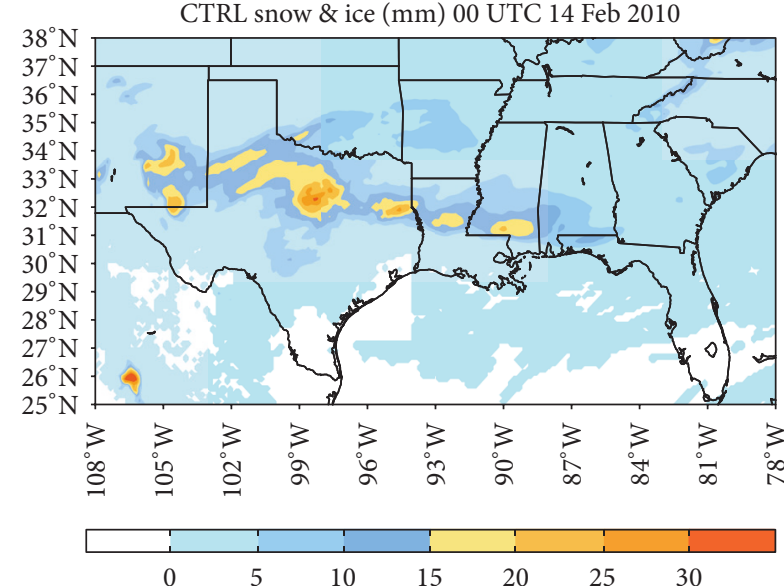

(a)

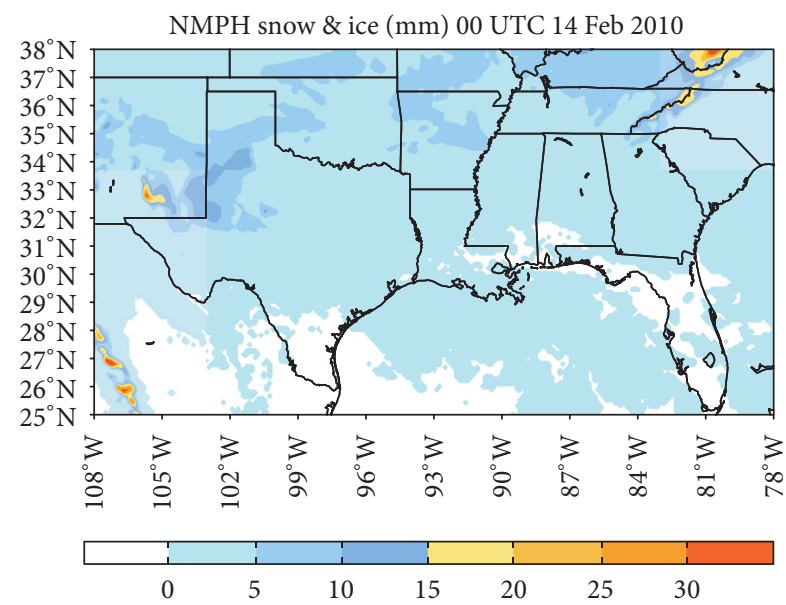

(c)

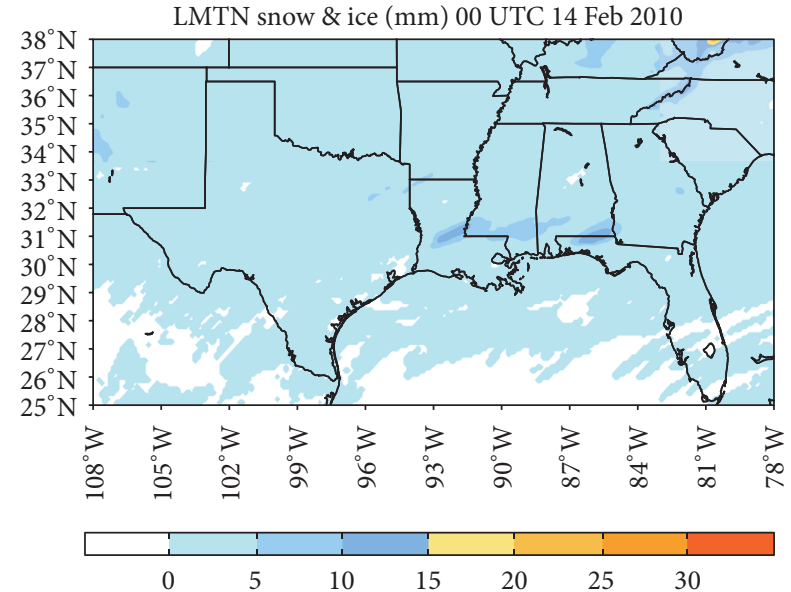

(b)

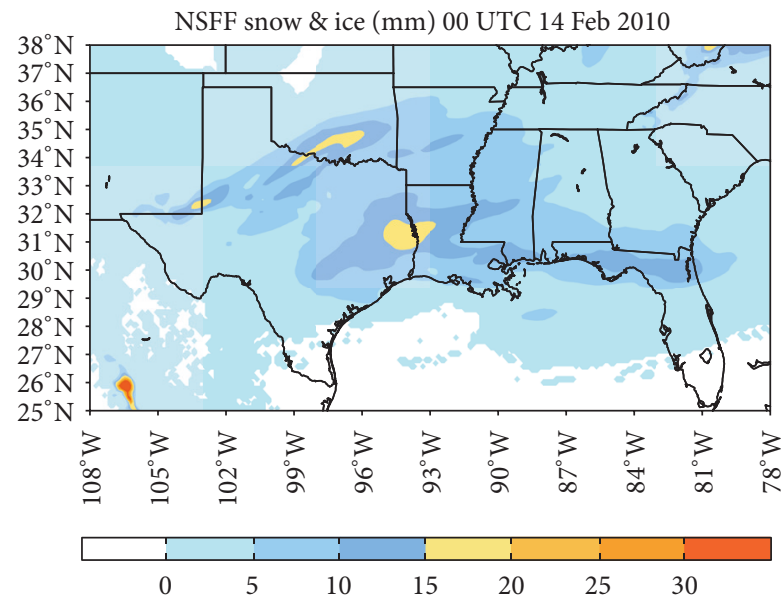

(d)

FIGURE 22: Simulated $(12 \mathrm{~km}$ ) total snow and ice accumulation (mm) from on 0000 UTC 14 February 2010 on (a) the control experiment, (b) the terrain reduction experiment, (c) no microphysics heating experiment, and (d) no surface flux experiment. 
(NMPH) to test the effects of latent heating. (3) Surface heat and moisture flux was turned off (NSFF) to test its sensitivity to the development on the overall intensity of the snowstorm. A comparison was presented to give an idea of how big of a role each parameter plays in this snowstorm case study.

The LMTN experiment resulted in a weaker baroclinic zone and there was a significant decrease in snowfall accumulations. The heaviest area of snowfall that takes place over Texas prior to cyclogenesis in the CTRL is because of the synergistic interactions between the polar, subtropical, and arctic air streams over the nearby elevated topography. Cold air damming against the Sierra Madre Mountains in Mexico is just as important for heavy southern snowstorms as the Appalachian Mountains are to Nor'easters, although having an abundance of arctic air across the deep south for a prolonged period of time is quite rare. The height of the Sierra Madre Oriental and Texas plateau enhances snowfall accumulation amounts over the lower Mississippi River Valley resulting in a record breaking snowfall event due to the orographic effects. However, further eastward, for states like Louisiana, Mississippi, and Alabama, the lack of latent heating seems to play an even bigger role for snowfall accumulations in the NMPH run across this area than the LMTN experiment. The NSFF case has the least amount of influence of all the sensitivity experiments and resembles the banding frozen precipitation of the CTRL experiment spanning from Texas to northern Florida. However, the NSFF snow and ice accumulations are not as intense as the CTRL case. Without latent heating and high level terrain, little snowfall occurs. These sensitivity experiments indicate complex coupling between terrain blocking, latent heating, surface fluxes, jet formations/circulations, and banding mesoscale precipitation processes.

\section{Conflicts of Interest}

The authors declare that there are no conflicts of interest regarding the publication of this paper.

\section{Acknowledgments}

The first author would like to thank the following Ph.D. committee members at North Carolina Agricultural and Technical State University: Drs. L. Liu, A. Mekonnen, J. Zhang, and first author's advisor Y.-L. Lin. Special thanks are due to Dr. M. Kaplan for his time and expertise, which helped greatly improve this manuscript and is highly appreciated. This research was funded by Department of Education Title III HBGI program and partially supported by the NOAA Cooperative Agreement no. NA06OAR4810187 and National Science Foundation Awards AGS-1265783, CNS-1126543, and CNS-1429464.

\section{References}

[1] T. L. Mote, D. W. Gamble, S. J. Underwood, and M. L. Bentley, "Synoptic-scale features common to heavy snowstorms in the Southeast United States," Weather and Forecasting, vol. 12, no. 1, pp. 5-23, 1997.
[2] S. M. Hunter, S. J. Underwood, R. L. Holle, and T. L. Mote, "Winter lightning and heavy frozen precipitation in the Southeast United States," Weather and Forecasting, vol. 16, no. 4, pp. 478490, 2001.

[3] L. F. Bosart, “The Presidents' Day snowstorm of 18-19 February 1979: a subsynoptic-scale event." Monthly Weather Review, vol. 109, no. 7, pp. 1542-1566, 1981.

[4] L. W. Uccellini, P. J. Kocin, R. A. Petersen, C. H. Wash, and K. F. Brill, “The Presidents' Day cyclone of 18-19 February 1979 (USA): synoptic overview and analysis of the subtropical jet streak influencing the pre-cyclogenetic period," Monthly Weather Review, vol. 112, no. 1, pp. 31-55, 1984.

[5] L. W. Uccellini, D. Keyser, K. F. Brill, and C. H. Wash, "The Presidents' Day cyclone of 18-19 Februarry 1979: influence of upstream trough amplification and associated tropopause folding on rapid cyclogenesis.," Monthly Weather Review, vol. 113, no. 6, pp. 962-988, 1985.

[6] L. W. Uccellini, R. A. Petersen, P. J. Kocin, K. F. Brill, and J. J. Tuccillo, "Synergistic Interactions between an Upper-Level Jet Streak and Diabatic Processes that Influence the Development of a Low-Level Jet and a Secondary Coastal Cyclone," Monthly Weather Review, vol. 115, no. 10, pp. 2227-2261, 1987.

[7] J. S. Whitaker, L. W. Uccellini, and K. F. Brill, "A model-based diagnostic study of the rapid development phase of the Presidents' Day cyclone," Monthly Weather Review, vol. 116, no. 11, pp. 2337-2365, 1988.

[8] L. W. Uccellini and P. J. Kocin, "The Interaction of Jet Streak Circulations during Heavy Snow Events along the East Coast of the United States," Weather and Forecasting, vol. 2, no. 4, pp. 289-308, 1987.

[9] P. J. Kocin, P. N. Schumacher, R. F. Morales, and L. W. Uccellini, "Overview of the 12-14 March 1993 Superstorm," Bulletin of the American Meteorological Society, vol. 76, no. 2, pp. 165-182, 1995.

[10] F. Mesinger, G. DiMego, E. Kalnay et al., "North American regional reanalysis," Bulletin of the American Meteorological Society, vol. 87, no. 3, pp. 343-360, 2006.

[11] Plymouth State Weather Center, "2010: Make Your Own: Product Generator for Real-Time and Archived Data," http:// vortex.plymouth.edu/myo.

[12] NOAA profiler network data, "2017: NOAA Wind Profiler Network (NPN) Data Stream to end August 2014," http://www .unidata.ucar.edu/blogs/news/entry/noaa_wind_profiler_network_npn.

[13] W. C. Skamarock, J. B. Klemp, J. Dudhia et al., "Description of the Advanced Research WRF Version 3," National Center for Atmospheric Research (NCAR) Technical Note, 2008.

[14] E. J. Mlawer, S. J. Taubman, P. D. Brown, M. J. Iacono, and S. A. Clough, "Radiative transfer for inhomogeneous atmospheres: RRTM, a validated correlated-k model for the longwave," Journal of Geophysical Research D: Atmospheres, vol. 102, no. 14, pp. 16663-16682, 1997.

[15] J. Dudhia, "Numerical study of convection observed during the Winter Monsoon Experiment using a mesoscale two-dimensional model," Journal of the Atmospheric Sciences, vol. 46, no. 20, pp. 3077-3107, 1989.

[16] G. Thompson, P. R. Field, R. M. Rasmussen, and W. D. Hall, "Explicit forecasts of winter precipitation using an improved bulk microphysics scheme. Part II. Implementation of a new snow parameterization," Monthly Weather Review, vol. 136, no. 12, pp. 5095-5115, 2008. 
[17] A. K. Betts, "A new convective adjustment scheme. Part I: Observational and theoretical basis," Quarterly Journal of the Royal Meteorological Society, vol. 111, pp. 1306-1335, 1986.

[18] A. K. Betts and M. J. Miller, "A new convective adjustment scheme. Part II: single column tests using GATE wave, BOMEX, ATEX and arctic air-mass data sets," Quarterly Journal of Royal Meteorological Society, vol. 112, no. 473, pp. 693-709, 1986.

[19] Z. I. Janjić, “The step-mountain eta coordinate model: further developments of the convection, viscous sublayer, and turbulence closure schemes," Monthly Weather Review, vol. 122, no. 5, pp. 927-945, 1994.

[20] G. L. Mellor and T. Yamada, "A hierarchy of turbulence closure models for planetary boundary layers," Journal of Atmospheric Sciences, vol. 31, pp. 1791-1806, 1974.

[21] G. L. Mellor and T. Yamada, "Development of a turbulence closure model for geophysical fluid problems," Reviews of Geophysics \& Space Physics, vol. 20, no. 4, pp. 851-875, 1982.

[22] Z. I. Janjić, "Nonsingular Implementation of the Mellor-Yamada Level 2.5 Scheme in the NCEP Meso Model," NCEP Office Note, vol. 437, no. 61, 2001.

[23] F. Chen and J. Dudhia, "Coupling and advanced land surfacehydrology model with the Penn State-NCAR MM5 modeling system. Part I: model implementation and sensitivity," Monthly Weather Review, vol. 129, no. 4, pp. 569-585, 2001.

[24] M. B. Ek, K. E. Mitchell, Y. Lin et al., "Implementation of Noah land surface model advances in the National Centers for Environmental Prediction operational mesoscale Eta model," Journal of Geophysical Research, vol. 108, no. D22, p. 8851, 2003.

[25] T. R. Loveland, B. C. Reed, J. F. Brown et al., "Development of a global land cover characteristics database and IGBP DISCover from $1 \mathrm{~km}$ AVHRR data," International Journal of Remote Sensing, vol. 21, no. 6-7, pp. 1303-1330, 2000.

[26] Weather Prediction Center, "2010: February 11-13 2010 Southern Plains to Southeast Snow," http://www.wpc.ncep.noaa.gov/ winter_storm_summaries/graphics/2009_2010/feb11_13_2010 .html.

[27] Y.-L. Lin, Mesoscale Dynamics, Cambridge University Press, 2007.

[28] R. E. Davis and R. Dolan, "Noreasters," American Scientist, vol. 81, no. 6, pp. 428-439, 1993.

[29] A. K. Betts and F. J. Dugan, "Empirical Formula for Saturation Pseudoadiabats and Saturation Equivalent Potential Temperature," Journal of Applied Meteorology, vol. 12, no. 4, pp. 731-732, 1973.

[30] D. M. Schultz and P. N. Schumacher, "The use and misuse of conditional symmetric instability," Monthly Weather Review, vol. 127 , no. 12 , pp. 2709-2732, 1999. 

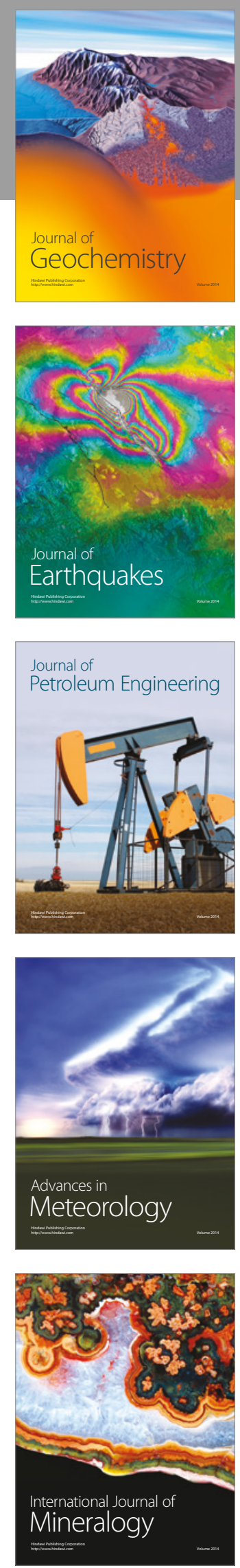
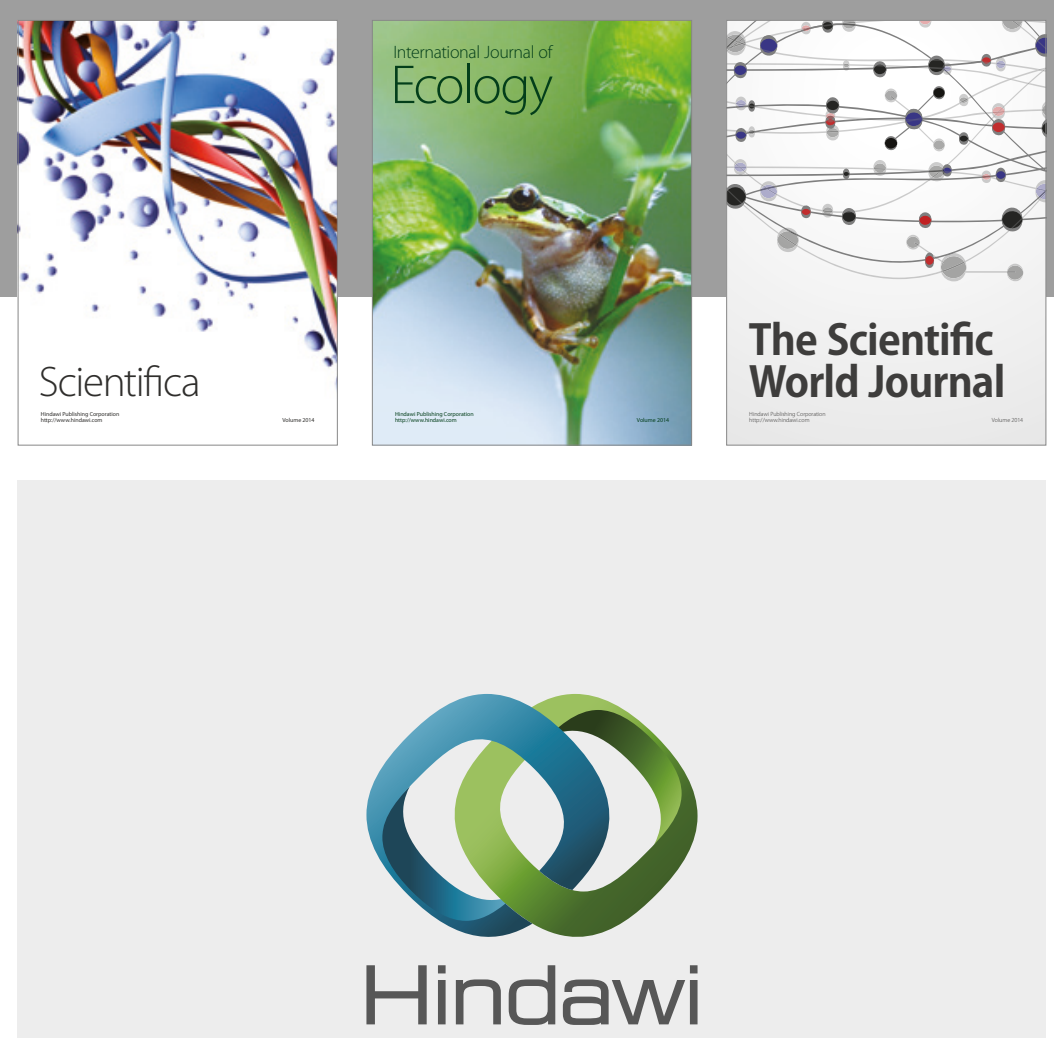

Submit your manuscripts at

https://www.hindawi.com
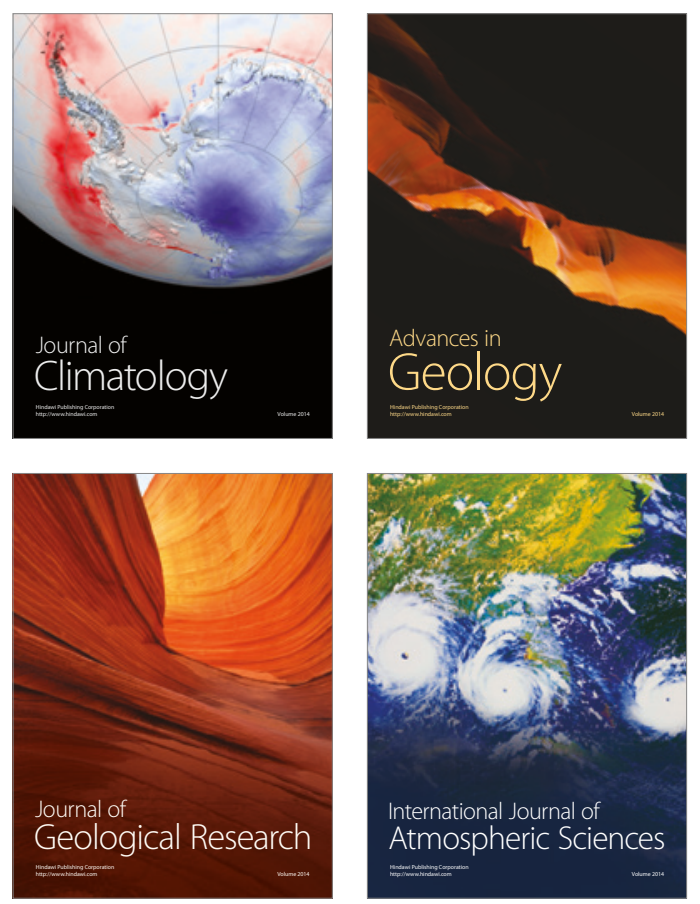

The Scientific

World Journal
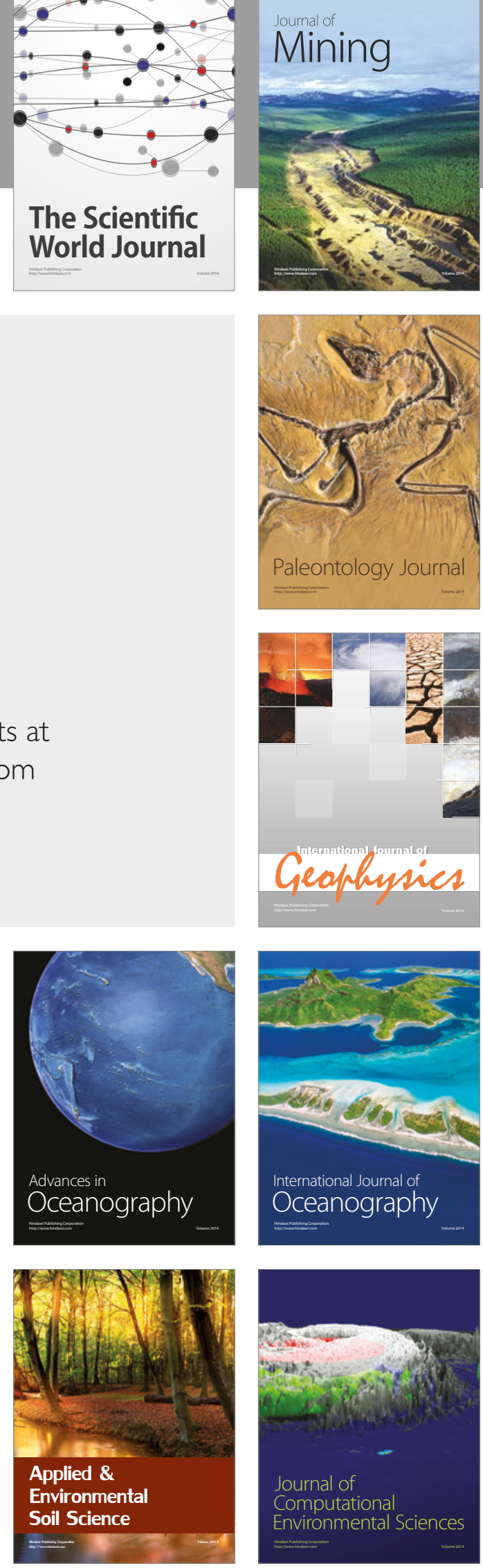